\title{
Rab5 and Rab4 Regulate Axon Elongation in the Xenopus Visual System
}

\author{
Julien Falk, Filip A. Konopacki, Krishna H. Zivraj, and Christine E. Holt \\ Department of Physiology, Development, and Neuroscience, Anatomy Building, University of Cambridge, Cambridge CB2 3DY, United Kingdom
}

The elongation rate of axons is tightly regulated during development. Recycling of the plasma membrane is known to regulate axon extension; however, the specific molecules involved in recycling within the growth cone have not been fully characterized. Here, we investigated whether the small GTPases Rab4 and Rab5 involved in short-loop recycling regulate the extension of Xenopus retinal axons. We report that, in growth cones, Rab5 and Rab4 proteins localize to endosomes, which accumulate markers that are constitutively recycled. Fluorescence recovery after photo-bleaching experiments showed that Rab5 and Rab4 are recruited to endosomes in the growth cone, suggesting that they control recycling locally. Dynamic image analysis revealed that Rab4-positive carriers can bud off from Rab5 endosomes and move to the periphery of the growth cone, suggesting that both Rab5 and Rab4 contribute to recycling within the growth cone. Inhibition of Rab4 function with dominant-negative Rab4 or Rab4 morpholino and constitutive activation of Rab5 decreases the elongation of retinal axons in vitro and in vivo, but, unexpectedly, does not disrupt axon pathfinding. Thus, Rab5- and Rab4-mediated control of endosome trafficking appears to be crucial for axon growth. Collectively, our results suggest that recycling from Rab5-positive endosomes via Rab4 occurs within the growth cone and thereby supports axon elongation.

\section{Introduction}

The speed of axon elongation differs between neurons but also undergoes stereotyped changes for the same axon during its journey (Gomez and Spitzer, 1999; Goldberg, 2003; PorteraCailliau et al., 2005; Mire et al., 2012). In Xenopus, for example, axons from the retinal ganglion cells (RGCs) change from fast to slow extension when they enter the tectum, the brain region they innervate (Harris et al., 1987). Recycling of internalized molecules is one of the mechanisms controlling growth cone motility and axon extension (Kamiguchi and Lemmon, 2000; Kamiguchi and Yoshihara, 2001; Bonanomi et al., 2008). Changes in the extent and pathways of recycling seem to parallel the decrease of axon growth that occurs as neurons mature (Bonanomi et al., 2008). Thus, identification

Received Feb. 27, 2013; revised Sept. 30, 2013; accepted Nov. 6, 2013.

Author contributions: J.F. and C.E.H. designed research; J.F., F.A.K., and K.H.Z. performed research; J.F. contributed unpublished reagents/analytic tools; J.F. and F.A.K. analyzed data; J.F. and C.E.H. wrote the paper.

This work was supported by a postdoctoral EMBO fellowship (J.F.) and a Wellcome Trust Programme Grant (C.E.H.). We thank Hanno Svoboda and Kin-Mei Leung for their help with experiments related to the project. We thank T. Dyl and A. Pungaliya for egg fertilization and DNA preparations; and A. Dwivedy and L. Leung for in vivo time-lapse imaging advice. We also thank C. Wilkinson for the PCS2-GFP and RFP plasmids; C.P. Heisenberg for the CA-zRab5c construct; J. Jullien for dRab5-GFP construct; B.0. Van Deurs GFP-Rab7-wt and DN constructs; and A. Hayakawa and H. Stenmark for GFP-FYVE construct. We thank L. Tamagnone and L. Lanzetti for their initial support on the project proposal; and L. Lagnado and B. Odermatt for many insightful discussions. We thank L. Strochlic, L. Poggi, D. Maurus, as well as all the members of the Harris/Holt laboratory for their input and support. We warmly thank V. Castellani and E. Derrington for critically reading the manuscript.

The authors declare no competing financial interests.

This article is freely available online through the J Neurosci Author Open Choice option.

Correspondence should be addressed to Julien Falk, CGphiMC UMR CNRS 5534, University of Lyon, Université Claude Bernard Lyon 1, 69622 Villeurbanne, France. E-mail: julien.falk@univ-lyon1.fr.

DOI:10.1523/JNEUROSCI.0876-13.2014

Copyright (c) 2014 Falk et al.

This is an Open Access article distributed under the terms of the Creative Commons Attribution License (http://creativecommons.org/licenses/by/3.0), which permits unrestricted use, distribution and reproduction in any medium provided that the original work is properly attributed. of the endosomes and the effectors that regulate local recycling pathway could provide important insights into how axons modulate their growth.

Recycling is classically defined as "rapid" or "slow," depending on whether it occurs directly from the sorting endosomes ("short loop") or from the endocytic recycling compartment (ERC; long loop), respectively. Efficient recycling requires fully functional sorting endosomes so that membranes can be sorted and correctly addressed to these two pathways. Consequently, recycling depends on small Rab GTPases, such as Rab5, that control sorting endosome biogenesis or function (Stenmark et al., 1994; Ullrich et al., 1996). Several subsequent trafficking steps along the slow and fast recycling routes also rely on particular Rabs. While Rab35 regulates both fast and slow recycling others only contribute to one pathway. Rab11, Rab8, Rab10, Rab14, and Rab22a control recycling from the ERC (Ullrich et al., 1996; Ren et al., 1998; Weigert et al., 2004; Glodowski et al., 2007; Grant and Donaldson, 2009). Conversely, Rab4 preferentially regulates direct recycling from the sorting endosomes (van der Sluijs et al., 1992; Pagano et al., 2004; White et al., 2007; Stenmark, 2009). In neurons, Rab11 was shown to control transport of growthpromoting receptors from the soma to the axon and thereby support axon extension ( Ascaño et al., 2009; Eva et al., 2010). In contrast, little is known about short-loop recycling in developing axons, although it would be ideally adapted to mediate local recycling. Rab4 is found in developing axons, and it controls recycling at the synapse (Holmes et al., 2006; Brown et al., 2007; Hoogenraad et al., 2010; Li et al., 2012; Nakazawa et al., 2012; Roman-Vendrell et al., 2012), but its contribution to axon elongation has not been investigated.

In the present work, we investigated the contribution of shortloop recycling to the elongation of Xenopus RGC axons. Live 
Table 1. List of the primers used to generate the Xenopus Rab constructs

\begin{tabular}{|c|c|c|}
\hline Construct name & Forward primer & Reverse primer \\
\hline EGFP- and mRFP-Rab5a & GATCTC GAGCTC CATGGCAAACCGAGGCGGAG & ATTACA CCCGGG GATGGCACAAAGGCCAAGACAGG \\
\hline EGFP-and mRFP-Rab5c & TCAGAT CTCGAG CATGGCCAGTAGAGGAACAAGCG & ACTGCAGAATTC GAAGTGACTGTAGAGCGACGGTG \\
\hline CA-Rab5c (Q80L) & CTGGGACACCGCAGGGCTGGAGAGGTACCACAG & CTGTGGTACCTCTCCAGCCCTGCGGTGTCCCAG \\
\hline EGFP- and mRFP-Rab4 & GATCTC GAGCTC G TCTGAGACATACGACTTCCTGTTCA AG & ATTACA CCCGGG ATGAGCAAGCTTCCAGGGCAAG \\
\hline CA-Rab4 (067L) & CTGGGATACGGCAGGACTGGAGAGATTCAGATCGG & CCGATCTGAATCTCTCCAGTCCTGCCGTATCCCAG \\
\hline DN-Rab4 (N121I) & CTTGTGTGGAATCAAAAAAGATTTGGATGCTGATCGAGAGGTG & САCCTCTCGATCAGCATCCAAATCTTTTTTGATTCCACACAAG \\
\hline EGFP- and mRFP-Rab7a & GATCTC GAGCTC ACG AG C AGGAAGAAAGTGCTGCT GAAGGTC & GTGGAT CCCGGG GTTAGTGAAGGACTCC $\overline{G G C T T C G}$ \\
\hline CA-Rab7 (Q67L) & GATATGGGACACAGCTGGGCTGGAGAGGTTCCAATCG & TGGAACCTCTCCAGCCCAGCTGTGTCCCATATCTGC \\
\hline DN-Rab7 (T22N) & GGGTTGGCAAAAACTCTCTCATGAACCAGTATGTG & СACATACTGGTTCATGAGAGAGTTTTTGCCAACCCC \\
\hline EGFP- and mRFPRab11a & CACTGA GAGCTC G ATGGGTACCAGGGACGACG & GTGGAT CCCGGG AAAGAGTCCAGGGCAGGACG \\
\hline EGFP- and mRFP-Rab11b & TCAGAT CTCGAG CGGAGCCAGAGATGACGAATACG & ACTGCAGAATTC CTCAGACTACGTCAGGTCC \\
\hline
\end{tabular}

The extra 5 ' sequences that contain the restriction site are in italics. The codons that were modified by site-directed mutagenesis are underlined.

imaging of the local dynamics of Rab5 and Rab4 provided evidence that they participate in a recycling loop within the growth cone. Therefore, we investigated the function of Rab5 and Rab4 during axon elongation. Mutants of Rab5 and Rab4 that should block short-loop recycling slowed down axon extension in vitro and in vivo. Consistent with this, morpholino-mediated knockdown of Rab4 decreased axon extension. Collectively, our data suggest that Rab5 and Rab4 participate in a recycling loop within the growth cone that controls the speed of axon elongation.

\section{Materials and Methods}

Embryos. Xenopus laevis embryos of either sex were obtained by in vitro fertilization, raised in $0.1 \times$ Modified Barth's Saline at $14-20^{\circ} \mathrm{C}$ and staged according to Nieuwkoop and Faber (1994). The Ethical Review Committee of University of Cambridge approved the animal experiments.

Mammalian and zebrafish Rab constructs. Zebrafish CA-zRab5c construct was a kind gift from Carl-Philipp Heisenberg (Institute of Science and Technology, Klosterneuburg, Austria; Ulrich et al., 2005). dRab5GFP was a kind gift from Jerome Jullien (Univeristy of Cambridge, Cambridge, England; Jullien and Gurdon, 2005). GFP-Rab7-WT and dominant-negative (DN) constructs were a kind gift from Bo Van Deurs (Kobenhavns Universitet, Copenhagen, Denmark; Bucci et al., 2000). 2xFYVE (SARA)-GFP and FYVE (Hrs)-GFP were gifts from Akira Hayakawa (University of Massachusetts Medical School, Worcester, MA) and Harald Stenmark (University of Oslo, Oslo, Noway), respectively (Raiborg et al., 2001; Hayakawa et al., 2007).

Fluorescent fusion proteins and Xenopus Rab mutants. Full-length Xenopus IMAGE clones for Rab5a (IMAGE: 4889660), Rab5c (IMAGE: 4964226) Rab1lb (IMAGE: 4724682), Rablla (IMAGE: 7019309), Rab7a (IMAGE: 5511069), and Rab4 (IMAGE: 4930282) were purchased from Geneservice. pCS2P+EGFP and monomeric RFP (mRFP) plasmids were a gift from Christopher Wilkinson (University of London, London, England; Zolessi et al., 2006).

The coding sequences of the different Xenopus Rabs (xRabs) were amplified by high-fidelity PCR with their respective primers (Table 1) Rab4, Rab5a, Rab7a, and Rab1la PCR fragments were digested with SacI and XmaI, and cloned into the pCS2P+GFP and + mRFP plasmids to obtain "in frame" fusions of GFP or RFP at the N terminus of the Rab proteins. Rab5c and Rab11b coding sequences were cloned into Xhol and EcoRI sites.

Point mutations of GFP-Rab5c, GFP-Rab4, GFP-Rab7a, and RFPRab4 were performed by site-directed mutagenesis. To identify the amino acids that needed to be mutated, Xenopus, Zebrafish, mouse, and human protein sequences of the different Rabs were aligned with ClustalW2. The glutamines at the end of the "G3 box" (GTP/ $\mathrm{Mg}^{2+}$ binding site) in position 80 in xRab5c and 67 in xRab4 and xRab7a were changed into leucine to inhibit Rab GTPase activity (constitutively active form). The asparagine 121 from the "G4 box" of Xenopus Rab4 was mutated into isoleucine to inhibit GTP binding (dominant-negative form). The threonine at position 22 ("G1 box") was changed into asparagine to impair GTP binding of Xenopus Rab7a. The primers used are listed in Table 1 (the mutated codon is underlined). Primer design and PCR amplification were performed according to the Quickchange reference protocol (Stratagene). After 14 cycles of amplification, Dpn1 enzyme (14 units) was added to the PCR mix and incubated for $1 \mathrm{~h}$ at $37^{\circ} \mathrm{C}$ to digest the template plasmid. All constructs were sequence verified (DNA core facility, Biochemistry Department, University of Cambridge). Sequence analysis and map generation were done in APE and pDraw software. Expression plasmids were prepared from Escherichia coli cultures using the Qiagen Midi DNA preparation kit (Qiagen) and resuspended in water.

Morpholino injection. Fluorescein-tagged translation blocking morpholino oligonucleotides (MOs) against the Rab4 RNA sequence BC044974 (5'-GGAAGTCGTATGTCTCAGACATGAT-3') were designed and synthetized by GeneTools. Control MOs were standard fluorescein-tagged control MOs from GeneTools (5'-CCTCTTACCTCA GTTACAATTTATA-3'). Twelve nanograms of MO were injected into both dorsal animal blastomeres of the four-stage embryos as described previously (Leung and Holt, 2008).

Electroporation. Eye-targeted electroporation was performed in stage 26-28 embryos as previously described (Falk et al., 2007). Anesthetized embryos were placed yolk up in the longitudinal channel of a crossshaped Sylgard chamber so that the eyes faced the homemade platinum electrodes. A total of $10-30 \mathrm{nl}$ of DNA solution $(0.6-1 \mu \mathrm{g} / \mu \mathrm{l}$ for endosome labeling or $2-2.5 \mu \mathrm{g} / \mu \mathrm{l}$ for functional assays) was injected between the eye and the brain. Accuracy and reproducibility of injection were assessed by fast green diffusion within the optic vesicle. A $1 \mathrm{~Hz}$ series of eight pulses ( $18 \mathrm{~V}$ and $50 \mathrm{~ms}$ long) was delivered by a square wave pulse generator (TSS20 OVODYNE Electroporator, Intracel). Embryos were returned to $0.1 \times$ MBS (Modified Barth's Saline) and grown overnight at $18^{\circ} \mathrm{C}$. The next day, embryos were kept at $18^{\circ} \mathrm{C}$ if used to prepare wholeeye culture or grown at room temperature (RT) until they reached the desired stage if used to analyze axon elongation in vivo.

Cell culture. Whole eyes were dissected from stage 33/34 embryos and were cultured as described previously (Campbell et al., 2001). Dissected eyes were plated on coverslips coated with $10 \mu \mathrm{g} / \mathrm{ml}$ poly-L-lysine (PLL) and $10 \mu \mathrm{g} / \mathrm{ml}$ laminin (Sigma), and were grown at $20^{\circ} \mathrm{C}$ for $14-24 \mathrm{~h}$ in $60 \% \mathrm{~L} 15, \mathrm{pH} 7.6$, with penicillin-streptomycin-fungizone (Invitrogen). Dissociated cells were prepared as described previously (Falk et al., 2007). Briefly, electroporated eyes were dissected at stage 33/34, cut in halves, and trypsinized for $2 \mathrm{~min}$, and cells were mechanically dissociated with a fire-polished Pasteur pipette. Dissociated cells were cultured in 60\% L15 with $10 \%$ fetal bovine serum (Invitrogen) on poly-L-lysine/laminincoated glass coverslips.

Dorsal root ganglion cultures and primaquine treatment. Dorsal root ganglia (DRGs) were dissected in ice-cold HBSS $\left(\mathrm{Ca}^{2+} / \mathrm{Mg}^{2+}\right.$-free, Invitrogen) from E4.5 chick embryos of either sex (Gallus gallus; EARL Morizeau).

Dissected DRGs were incubated with $2.5 \mathrm{mg} / \mathrm{ml}$ trypsin (T5266, Sigma) in $\mathrm{Ca}^{2+} / \mathrm{Mg}^{2+}$-free HBSS for $5 \mathrm{~min}$ (E4.5 embryos) at $37^{\circ} \mathrm{C}$. DNase $1(0.033 \mathrm{mg} / \mathrm{ml}$; DN25, Sigma) was added, and DRGs were returned to $37^{\circ} \mathrm{C}$ for an additional $10 \mathrm{~min}$. After neutralization with serum, trypsin-containing medium was removed, and DRGs were mechanically dissociated. Cells $\left(0.3 \times 10^{5}\right)$ were plated on $13 \mathrm{~mm}$ PLL-coated and 
laminin-coated coverslips (PLL: $50 \mu \mathrm{g} / \mathrm{ml}$; laminin: $10 \mu \mathrm{g} / \mu \mathrm{l}$; Sigma) and cultured in F12 $+10 \%$ fetal calf serum $+1 \%$ penicillin/streptomycin $+50 \mathrm{ng} / \mathrm{ml}$ nerve growth factor (N0513, Sigma).

DRG neurons were loaded with FM4-64 for 3 min in F12. Primaquine $(0.068 \mathrm{~mm})$ was added either $10 \mathrm{~min}$ before loading (internalization assay) or during the recycling step $(0,5$, and $15 \mathrm{~min})$. After fixation, $z$-stacks of growth cones were acquired at $40 \times$ [numerical aperture (NA), 1.3] on an FV1000 spectral confocal microscope (Olympus). Quantifications were done as described for RGC growth cones.

For outgrowth assays, primaquine was added $1.5 \mathrm{~h}$ after plating and fixed in $2 \%$ paraformaldehyde (PFA) $5 \mathrm{~h}$ after plating. Neurites were labeled with anti-neurofilament (HB4H6, Hybridoma Bank). To minimize sampling bias, $5 \times 5$ image montages were randomly acquired from different positions on the coverslip. Neurite length was quantified from the neurofilament staining in ImageJ using NeuronJ plugin (Meijering et al., 2004).

Immunostaining and Western blotting. Cultures were fixed in freshly prepared 2\% paraformaldehyde $/ 7.5 \%$ sucrose in PBS. Cells were permeabilized in PBS with $0.3 \%$ Triton X-100 for 10 min at RT, and blocked for $60 \mathrm{~min}$ at room temperature in PBS with 5\% goat serum and $1 \%$ bovine serum albumin (BSA) or 1\% fish gelatin (Sigma) for Rab5 labeling (Woo and Gomez, 2006). Cultures were incubated with the primary antibody diluted in blocking solution for $2 \mathrm{~h}$ at RT. Antibodies were used at the following dilutions: $10 \mu \mathrm{g} / \mathrm{ml}$ for anti-Rab7 (R8779, Sigma); $2.5 \mu \mathrm{g} / \mathrm{ml}$ for anti-Rab4 (610888, BD Transduction Laboratories; Strachan and Condic, 2004; Hoogenraad et al., 2010; Yamamoto et al., 2010; Nakazawa et al., 2012); and $5 \mu \mathrm{g} / \mathrm{ml}$ for anti-Rab5 (610281, BD Transduction Laboratories; Woolworth et al., 2009; Nakazawa et al., 2012). After three 10-min-long PBS washes, Cy3-conjugated goat anti-mouse (Calbiochem) diluted at 1:700 in PBS with 5\% goat serum and 1\% BSA was incubated for $45 \mathrm{~min}$. These antibodies were considered as specific since labeling intensity increased in axons overexpressing the corresponding GFP-Rab and colocalized with the GFP-positive vesicles.

Stage 37 Xenopus embryos were anesthetized, and their brains and eyes were dissected out. The tissue was dissociated in RIPA buffer with protein inhibitors (both from Sigma). The lysates, cleared by centrifugation $(10,000 \times g, 10 \mathrm{~min})$, were mixed 1:1 with $2 \times$ Laemmli buffer, heated to $90^{\circ} \mathrm{C}$ for $10 \mathrm{~min}$, and loaded on $12 \%$ mini protean gel (Bio-Rad). Following a wet transfer, the nitrocellulose membranes were blocked in 5\% skimmed powdered milk in TBS-T. The membranes were incubated in the blocking solution containing the primary antibodies [anti-Rab4 (catalog \#610888) at $250 \mathrm{ng} / \mathrm{ml}$; and anti-Rab5 (catalog \#610281) at 500 $\mathrm{ng} / \mathrm{ml}$; both from BD Transduction Laboratories) for $2 \mathrm{~h}$ at RT, washed $3 \times 10 \mathrm{~min}$ in TBS-T, followed by incubation with secondary anti-mouse $\operatorname{HRP}(1: 5000,60 \mathrm{~min}$ at RT). The membranes were then washed $3 \times 10$ min in TBS-T, and the signal was revealed using ECL2 Western Blotting substrate (Pierce) on GE Healthcare Hyperfilm ECL films.

Biotinylation, FM dyes, and Lysotracker labeling. Biotinylation was performed as described previously (Diestel et al., 2007). Sulfo-NHS-SSbiotin $(0.2 \mathrm{mg} / \mathrm{ml}$ in PBS; 21328, Thermo Fisher Scientific) was incubated for $20 \mathrm{~min}$ at $4^{\circ} \mathrm{C}$. Unbound biotin was quenched by washing the cells three times with $50 \mathrm{~mm}$ glycine in TBS $\left(4^{\circ} \mathrm{C}\right)$. One coverslip was directly fixed to check the level of biotinylation $\left(4 \% \mathrm{PFA}, 4^{\circ} \mathrm{C}, 30 \mathrm{~min}\right)$. Cultures were incubated for $20 \mathrm{~min}$ at room temperature to allow internalization. The remaining biotin was removed from the cell surface with $150 \mathrm{~mm}$ MESNA (sodium 2-mercapto-ethanesulfonate) diluted in 100 mM Tris- $\mathrm{HCl}, \mathrm{pH}$ 8.6, containing $100 \mathrm{~mm} \mathrm{NaCl}$ and $2.5 \mathrm{~mm} \mathrm{CaCl}_{2}(30$ $\min , 4^{\circ} \mathrm{C}$ ). Then cells were washed three times in TBS and three times in $\mathrm{L} 1560 \%\left(4^{\circ} \mathrm{C}\right)$. Two coverslips were fixed at this step to evaluate the level of surface and internalized biotin before recycling. Finally, cultures were incubated for $20 \mathrm{~min}$ at $37^{\circ} \mathrm{C}$ to allow internalized proteins to recycle. After fixation, cells were stained for $1 \mathrm{~h}$ with $0.4 \mu \mathrm{g} / \mathrm{ml}$ streptavidin-Cy3 (SA1010, Invitrogen) in PBS containing 5\% fetal bovine serum and 1\% BSA. Primaquine was used to block recycling during the internalization step and enhance the recycling (Roberts et al., 2001).

The levels of surface biotin were quantified on growth cones selected by phase contrast observations. Cy3 signals were acquired with OpenLab (Improvision) using the same settings, and care was taken to avoid pixel saturation (Piper et al., 2005; Zivraj et al., 2010). The mean gray value (i.e., the sum of the gray values of all selected pixels divided by the number of pixels) was measured within the manual outline of the growth cone area in ImageJ. The level of background fluorescence was measured in an adjacent area and subtracted to get the background-corrected mean intensity. Colocalization of internalized biotin and GFP-Rab4 and Rab5c-positive vesicles was examined in permeabilized growth cone before the recycling step.

Lysotracker (LysoTracker Red DND-99, Molecular probes) was diluted in culture medium to a final working concentration of $200 \mathrm{~nm}$ and applied for $30 \mathrm{~min}$ at RT (Diestel et al., 2007). Cultures were washed three times in medium before fixation.

FM dye (FM4-64 and FM1-43, Molecular Probes) labeling was performed as described by Diefenbach et al. (1999). Stock solution (5 mM in $\mathrm{H}_{2} \mathrm{O}$ ) was vortexed and centrifuged before dilution at 1:1000 in L15 60\%. FM dye solution was incubated for 1-2 min at RT, and coverslips were quickly washed three times in L15 60\% and either fixed in 4\% PFA or imaged live with a $z$-stack of the whole growth cone collected every $20 \mathrm{~s}$ over $5 \mathrm{~min}$. For the time-lapse recordings measuring the speed of recycling in FM dye-loaded growth cones, 14-bit images were acquired with Volocity at $100 \times(\mathrm{NA}, 1.4)$. Image quantification was performed using ImageJ: each stack was compressed, the ROI outlining the whole growth cone was drawn based on the differential interference contrast image; total FM dye fluorescence intensity was measured, and background (calculated using an identical ROI placed nearby) was subtracted.

Images were acquired at $100 \times$ magnification on a Nikon TE2000-U microscope equipped with Orca-ER camera (Hamamatsu) or on spinning disk confocal microscope (UltraVIEW ERS, IX81 inverted microscope, Olympus) equipped with an EM-CCD Camera (C9100-50, Hamamatsu) for colocalization studies.

Live Rab-positive endosome monitoring, measurement, and photobleaching. Imaging was performed at $100 \times(\mathrm{NA}, 1.4)$ on an Olympus IX81 inverted microscope equipped with the PerkinElmer Spinning Disk UltraVIEW ERS. Images were acquired on 14-bit EM-CCD camera (C9100-50, Hamamatsu) with Volocity 4.3.2 Build 23. Fast time-lapse monitoring was performed on growth cones from whole-eye cultures. Eyes were cultured in a $50 \mathrm{~mm}$ Glass-Bottom dish (MatTek) in L15 without phenol red (Invitrogen). Acquisitions were done at a rate of $0.5-2 \mathrm{~Hz}$ using the maximum sample protection mode. Acquisition time was kept under $100 \mathrm{~ms}$ with laser power usually set at $30 \%(488 \mathrm{~nm})$ and $50 \%(561 \mathrm{~nm})$. Dual imaging was performed in fast sequential mode using a dual-band emission filter [525 (W50), 640 (W120)]. Photobleaching was performed with the PhotoKinesis device in manually defined regions (typically, 30-40 cycles per region). The 16- to 8-bit image conversion and analysis were performed in ImageJ. The number of new endosomes in the bleached area was counted for each frame, and their origin (local or moving from the axon) was determined. For some movies, endosomes were tracked using ImageJ plugin (manual tracking; Fabrice Cordelières, Institut Curie, Orsay, France). The images presented in the figures were processed in the same way. Endosome number and apparent size were quantified in ImageJ. Particle analysis was performed within the manually defined regions of interest that outlined the whole growth cone or its subdomains (central and peripheral). The outlines were drawn from the phase or GFP images. The growth cone central domain was distinguished from the periphery based on the fact that it is thicker and organelle rich (phase dense). The intensity threshold was kept the same over all conditions to allow comparison.

In vitro and in vivo time-lapse microscopy. For in vivo experiments, stage 37/38 embryos were anesthetized, and the right optic tract and tectal area were exposed by carefully removing the right eye and skin epidermis, as described previously (Chien et al., 1993; Dwivedy et al., 2007; Falk et al., 2007). The heads of the embryos were mounted in a closed chamber filled with freshly made $1 \times \mathrm{MBS}, \mathrm{pH}$ 7.4-7.5, containing an anesthetic agent (0.3 mM MS222). A 1\% low-melting agarose was added to limit movement of the heads. Heads were maintained at RT during the observation and were viable for as long as required (up to $12 \mathrm{~h}$ ). To monitor axons in similar positions on the optic tract, axons overexpressing Rab4-DN were imaged a few hours after the control axons. $z$-stacks that encompassed the whole width were collected every 5 min for $1 \mathrm{~h}$ with a $20 \times$ lens (Nikon Plan Apo; NA, 0.75). 
In vitro time-lapse recordings were performed on whole eyes from stage $33 / 34$ that had been cultured overnight in a $50 \mathrm{~mm}$ Glass-Bottom dish (MatTek). Axons were imaged every $5 \mathrm{~min}$ for $45 \mathrm{~min}$ under an inverted TE2000 Nikon microscope equipped with an Orca-ER camera (Hamamatsu). Primaquine was added at the specified concentration (51 or $68 \mu \mathrm{M})$. The same axons were monitored before, during treatment with primaquine, and, in some experiments, after diluting it 10 times. Only the axons that have extended during the initial control recording (before primaquine addition) were quantified in these experiments. All the axons that had an identifiable growth cone were quantified in experiments where effects of Rab mutants were analyzed. Quantifications on Rab-transfected axons were performed only if the matching GFP control (same electroporation batch and culture) exhibited normal growth.

During in vitro and in vivo time-lapse imaging, illumination was reduced by using neutral density filter (ND4) to prevent phototoxicity and acquisition setting were the same for all conditions, so that we assayed axons with similar level of expression. Images were processed and analyzed in ImageJ. Growth cone position was recorded for each time point using the ImageJ point selection tool (auto-measure and auto-next slice option). The axon elongation rate was calculated in Excel from the total distance covered by the growth cone during the recording period.

Length measurement of transfected axons in vivo. Embryos were fixed in $4 \%$ formaldehyde overnight at $4^{\circ} \mathrm{C}$. To avoid the bias due to the delay of electroporation of the different constructs (usually $20 \mathrm{~min}$ ), the fixation of the different batches was timed accordingly. For whole-mount preparations, the brain was dissected out and split in half along the midline to exclude brains with extraretinal transfection. The two half-brains were mounted lateral side up. The transfected eye was also dissected and cut into two halves so that RGC transfection could be ascertained. Imaging and quantification were done only if bright GFP-positive RGCs could be seen. Images were acquired at $10 \times$ on a Nikon Eclipse $80 \mathrm{i}$ upright microscope, using constant video settings to compare similar level of construct expression. In cases where axons did not lie in a single focal plane, a $z$-stack was taken. Length of the longest or three longest GFP-positive axons was measured in OpenLab (Improvision). The length was set to 0 when GFP axons could be seen in the optic nerve or at the chiasm but not in the contralateral brain.

Microarrays of whole eyes. Twenty-five eyes of stage 32 Xenopus embryos were dissected, and their lenses removed. Total RNAs were extracted and biotin-labeled antisense RNAs were hybridized onto the $X$. laevis genome array from Affymetrix (GeneChip X. laevis genome array). RNA extraction, labeling, hybridization, and signal analysis were performed as previously reported (Zivraj et al., 2010). No RNA amplification was performed. The transcripts were considered as being present based on the Affymetrix detection call. This tests whether the signal intensities differ significantly between the perfect match and the mismatch probes for the same sequence (Archer and Reese, 2010).

Statistical analysis. Statistical analyses were performed in InStat3. Student's $t$ tests were performed on measurements that displayed a normal distribution. Values that did not follow a normal distribution were compared using a Mann-Whitney test.

\section{Results \\ RGC growth cones exhibit constitutive endocytosis and recycling that support elongation}

First, we checked whether local recycling occurs constitutively in the growth cone of RGC axons. To specifically monitor growth cones from RGCs during the phase of active growth, we cultured whole eyes from stage 33/34 embryos for 17-20 h. Cleavable biotin has been used to monitor internalization and recycling of surface proteins (Diestel et al., 2007). Surface proteins were biotinylated and the cleavable sulfo-NHS-SS-biotin was allowed to be internalized for $20 \mathrm{~min}$. At the end of the internalization period, biotin still present at the cell surface was cleaved with MESNA. Immediately after cleavage, biotin was detected in intracellular vesicles within the growth cone demonstrating that it had been internalized (Fig. $1 A$ ). Whereas no biotin could be de- tected at the surface of growth cones just after cleavage, some surface labeling could be observed 20 min later (Fig. $1 B, C$ ), indicative of return to the membrane. Signal intensity increased from $0.7 \pm 0.19$ arbitrary units (A.U.; $N=22$ ) to $3.3 \pm 0.44$ A.U. $(N=30$ growth cones) between 0 and $20 \mathrm{~min}$, which represents an increase of $485.5 \%\left(p=6 \times 10^{-6}\right)$. This shows that surface proteins are internalized and recycled in Xenopus growth cones. Given that axons are several hundred micrometers long and that the biotin uptake by the RGC soma in the explants is probably limited, the return of the biotin label to the cell surface is likely due to local recycling.

The relatively long incubation times required in the biotin recycling assay introduce a possible confound since fast events are not detected. To circumvent this limitation, we used the styryl dyes FM1-43 or FM4-64. FM dyes label membranes but are rapidly lost from the plasmalemma during washes. Thus, FM dyes stain vesicles that formed while the dye was present in the medium. After a 2 min exposure to FM dyes, many growth cones were loaded (Fig. 1D). Labeled vesicles, which accumulate in the central domain of the growth cone, included both large and small vesicles similar to findings in other neurons (Diefenbach et al., 1999; Bonanomi et al., 2005, 2008; Hines et al., 2012). Live monitoring of FM dye has been used to evaluate the rate of exocytosis of synaptic vesicles and recycling endosomes just after internalization (Diefenbach et al., 1999; Granseth et al., 2006; Tojima et al., 2007; Hines et al., 2012). Indeed, we found that FM labeling was lost upon exocytosis in growth cones. Time-lapse monitoring showed that FM dye staining decreased by $72.1 \pm 6.7 \%$ within 5 min after loading in RGC growth cones $(N=8$; Fig. $1 E)$.

To test whether local constitutive recycling contributes to axon elongation, we treated cultures with primaquine, a drug that has been shown to reversibly block recycling within minutes, notably of molecules that recycle via short-loop pathways (Stoorvogel et al., 1987; Reid and Watts, 1990; Roberts et al., 2001; Jones et al., 2009). Primaquine has been shown to block recycling efficiently at concentrations of 0.05-0.1 mM (Schwartz et al., 1984; van Weert et al., 2000; Bergtold et al., 2005). In our experiments, $0.068 \mathrm{~mm}$ primaquine, added immediately after FM dye loading, reduced the dye clearance by a factor of 2 . Primaquine-treated growth cones retained $63.3 \pm 8.9 \%$ of their initial signal while control growth cones had $27.9 \pm 6.7 \%(N=16 ; p=0.007$; Fig $1 E, F)$. Thus, primaquine efficiently blocks rapid constitutive recycling in RGC growth cones. Next, we assessed the acute effect of the drug on axon growth. Using time-lapse video-microscopy, we found that the addition of 0.05 or $0.068 \mathrm{~mm}$ primaquine strongly inhibited RGC axon growth. This effect was dose dependent and reversible as axon elongation recovered when primaquine was diluted out (Fig. 1G,H). Inhibition of elongation was detectable by $5 \mathrm{~min}$ after the addition of primaquine, further supporting a role of local recycling in RGC axon elongation.

Interestingly, in embryonic chick DRG neurons, $0.068 \mathrm{~mm}$ primaquine also inhibits constitutive recycling and reduces early neurite extension. The drug causes an increase of 2.3 times the FM signal after 5 min (control: $100 \pm 17$ A.U., $N=18$; primaquine: $264 \pm 26$ A.U., $N=27 ; p=1 \times 10^{-5}$, Mann-Whitney test) and a 3.1-fold increase after $15 \mathrm{~min}$ (control: $112 \pm 36$ A.U., $N=17$; primaquine: $346 \pm 64$ A.U., $N=20 ; p=9 \times 10^{-3}$, Mann-Whitney test). DRG neurons treated with primaquine show reduced early neurite extension (control: $72.8 \pm 2.62 \mu \mathrm{m}$, $N=756$; primaquine: $44.4 \pm 2.08 \mu \mathrm{m}, N=471 ; p=7 \times 10^{-4}$, Mann-Whitney test). Importantly, primaquine does not appear to affect endocytosis when applied 10 min before FM dye loading since the amount of internalized dye does not decrease. 


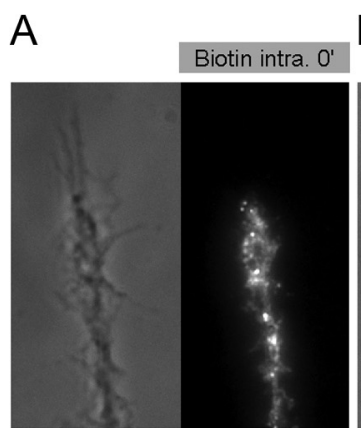

B

C

D
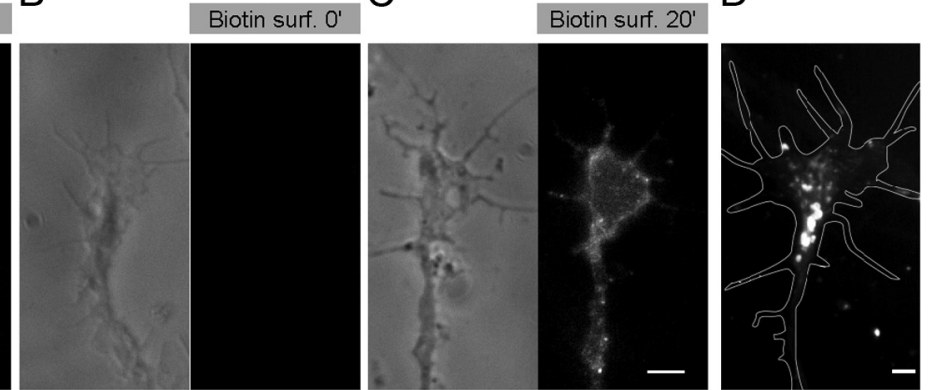

E
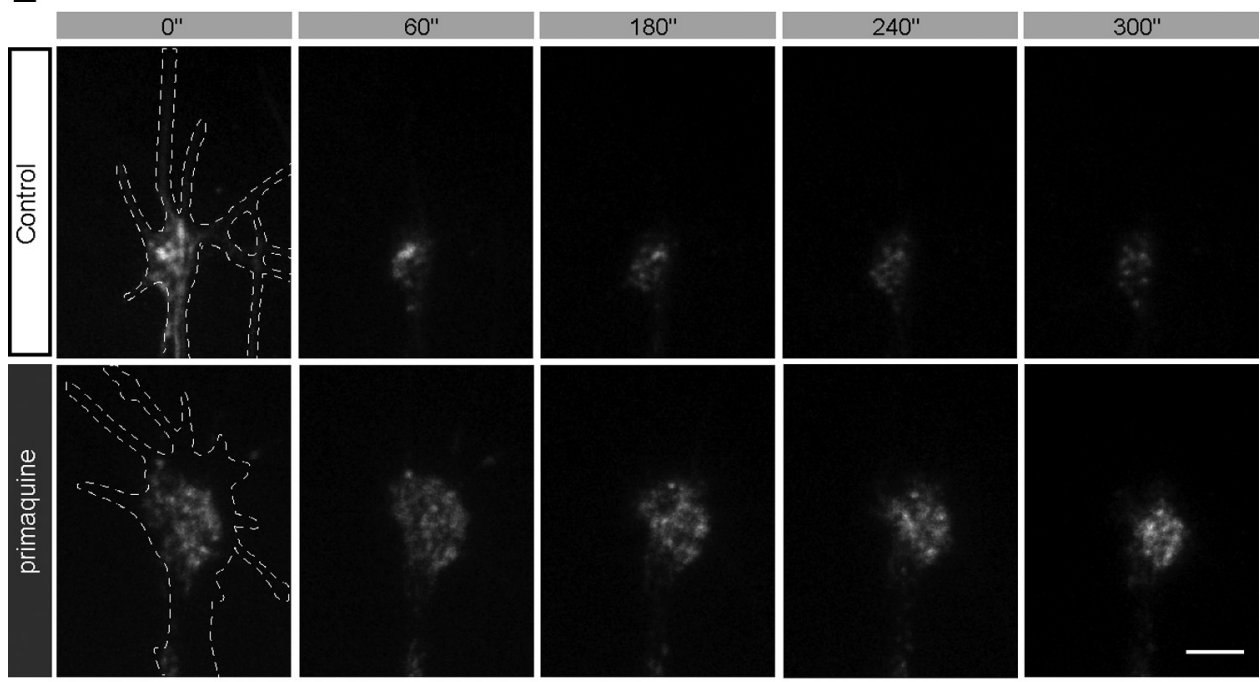

F

G
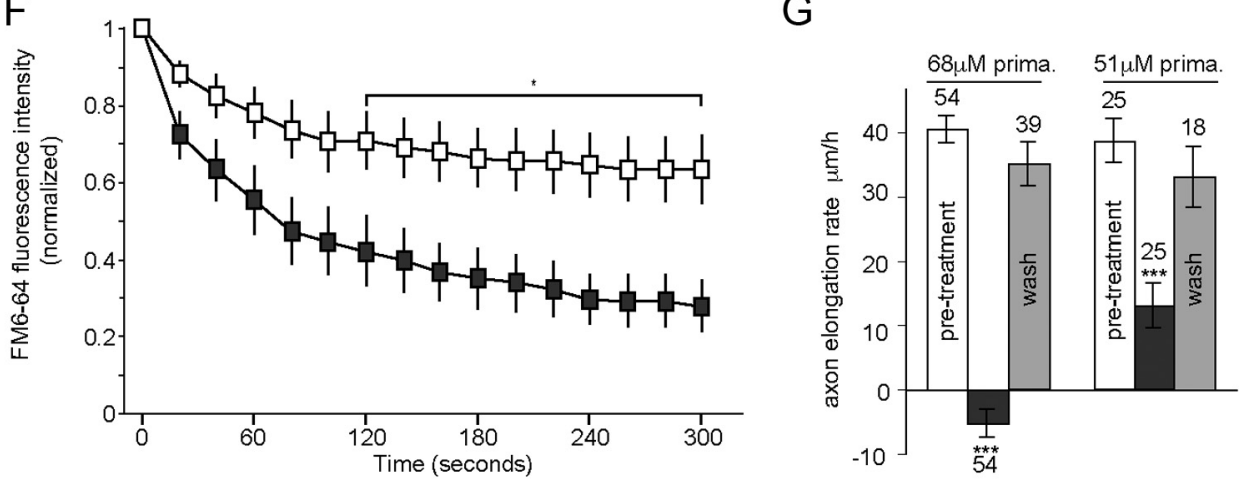

$\mathrm{H}$
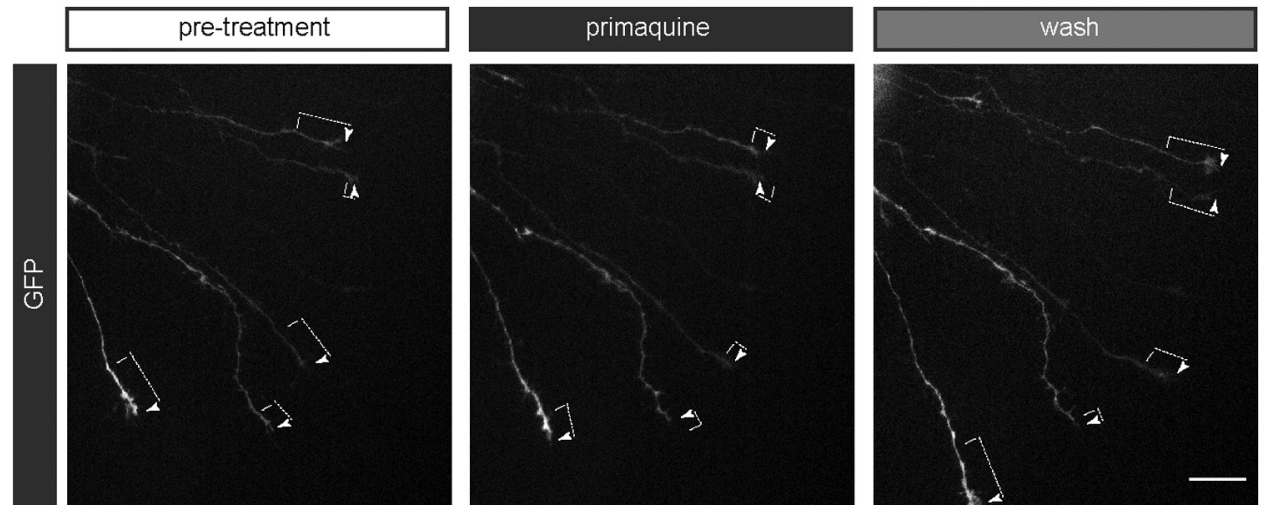

Figure 1. Constitutive recycling exhibited by Xenopus RGC growth cones is necessary for axon elongation in vitro. A-C, Biotinylated cell surface proteins are internalized and recycled in RGC growth cones. $A$, Biotinylated proteins were allowed to internalize for $20 \mathrm{~min}$, after which the biotin still present at the surface was removed by MESNA and intracellular accumulations of biotinylated protein were detected in permeabilized growth cones. $\boldsymbol{B}$, As expected, biotin labeling was barely detected just after MESNA treatment in nonpermeabilized growth cones. $\boldsymbol{C}$, Twenty minutes later, however, some biotin labeling is recovered at the surface of nonpermeabilized growth cones. $\mathbf{D}-\boldsymbol{F}$, Primaquine reduces local recycling. $\boldsymbol{D}$, FM dye is internalized in vesicles of different sizes that accumulate in the central domain of the growth cone; the white line delineates the outline of the growth cone. $\boldsymbol{E}$, The endosomes in growth cones were loaded with (Figure legend continues.) 
Table 2. Expression of some endosomal Rabs present in Xenopus retina from stage 32 embryos

\begin{tabular}{|c|c|c|c|c|c|c|}
\hline Affimetrix ID & Signal & GenBank & Gene symbol & Blast & GenBank Image clone & $\begin{array}{l}\text { Protein identity } \\
(\%)\end{array}$ \\
\hline XI0.3255.1.S1_at & 458,5 & BC041250 & Rab11b & & $\mathrm{BC} 041250$ & 97 \\
\hline X|0.12707.1.A1_at & 209,9 & B|312844 & Rab5 & Rab5c (NM_001087245) & BC056058 & 93 \\
\hline XI0.8290.1.S1_at & 150,7 & AW147912 & Rab5a & Rab5a (NM_001087066) & & 92 \\
\hline XI0.2484.1.S1_at & 146,5 & $\mathrm{BC} 043866$ & Rab5a & & $\mathrm{BC} 043866$ & 91 \\
\hline XI0.16236.1.S1_at & 119,1 & BC041759 & Rab35 & & & 78 \\
\hline XI0.18430.1.S1_at & 98,9 & BC044974 & Rab4a & & BC044974 & $85^{\#}$ \\
\hline XI0.9474.1.S1_at & 79,8 & BJ069024 & Rab7 & Rab7a (NM_001093537) & BC077884 & 96 \\
\hline
\end{tabular}

The table lists the probes that recognize transcripts for endosome-related Rabs, which were considered as "present" from the detection calls. When needed, Affymetrix reference sequences were blasted against Xenopus database to define which "isoform" the probe recognizes. The GenBank references of the image clones used in this study are listed. The last column presents the percentage of identity between the Xenopus and human proteins. Although the Xenopus Rab4 sequence is referenced as Rab4a, the pBlast score and the percentage of identity are higher with human Rab4b (86\%) than human Rab4a (85\%).

Altogether, this shows that a primaquine-sensitive pathway supports the local constitutive recycling that contributes to axon elongation. Overall, Xenopus embryonic RGC axons appear to be a good model to investigate the contribution of local recycling to axon growth and for characterizing some key effectors.

\section{Rab4-, Rab5-, and Rab11-positive endosomes present in RGC growth cones}

The cargoes are recycled from early endosomes back to the plasma membrane either directly or via "long-loop" recycling endosomes (Sönnichsen et al., 2000; Miaczynska and Zerial, 2002; Maxfield and McGraw, 2004; Grant and Donaldson, 2009; Stenmark, 2009). Thus, we checked whether Rab5-positive earlysorting endosomes, and fast (direct) Rab4-positive and slow Rab11-positive recycling endosomes are present in the RGC axon and growth cone.

Three Rab5 genes (Rab5a-Rab5c) and two Rab4 and Rab11 genes that code for different proteins with potentially divergent function have been characterized in mammals (Bucci et al., 1995; Barbieri et al., 2000; Lapierre et al., 2003; Prigozhina and Waterman-Storer, 2006; Scapin et al., 2006; Chen et al., 2009; Kaddai et al., 2009). Closely related homologs of all of these Rab proteins are found in Xenopus. The protein identity between $\mathrm{Xe}$ nopus and human proteins reaches $93 \%$ for Rab5c, 85\% for Rab4a, and 97\% for Rab11b. Although Rab5, Rab4, and Rab11 are thought to be ubiquitously expressed, their patterns of expression suggest that this may not always be the case in mouse embryos (www.genepaint.org) (Visel et al., 2004). Thus, we analyzed the transcriptome of whole retinas of stage 32 Xenopus by microarray. We found that Rab5a, Rab5c, Rab4, Rab1la, and Rab11b transcripts were classified as present by the Affymetrix

\footnotetext{
$\leftarrow$

(Figurelegend continued.) FM4-64 and time-lapse imaging was performed. The total loss of FM4 - 64 fluorescence over time represents the speed of local recycling as individual FM dyeloaded vesicles release their content to the environment. Note that primaquine $(0.068 \mathrm{~mm})$ reduces local recycling, as more FM dye is retained in primaquine-treated growth cones. The outlines of growth cones are shown in the white broken line. $\boldsymbol{F}$, The histogram shows the quantification of the total FM4 - 64 fluorescence intensity in the growth cones over time. Note that the difference in recycling between control and primaquine-treated growth cones becomes significant after 2 min. $\mathbf{G}, \boldsymbol{H}$, Primaquine blocks axon extension in vitro. $\mathbf{G}$, The histogram shows the quantification of the extension rate of axons before, during, and after primaquine treatment. Numbers above bars indicate the number of axons analyzed. $\boldsymbol{H}$, Snapshots from an in vitro time-lapse sequence illustrate the axon elongation rate of the same GFP-expressing axons in the absence of (left), in the presence of (middle), and after the dilution (right) of primaquine. For each axon, the dash and the arrowhead indicate the growth cone positions at the beginning and the end of the $45 \mathrm{~min}$ recording period, respectively. The dotted lines represent the distances covered by the growth cones during that time and exemplify the sharp inhibition of elongation observed in presence of primaquine. Error bars represent the SEM. ${ }^{*} p<0.05$; ${ }^{* * *} p<0.001$. Scale bars: $\boldsymbol{A}-\boldsymbol{C}, 5 \mu \mathrm{m} ; \boldsymbol{D}, 4 \mu \mathrm{m} ; \boldsymbol{E}, 5 \mu \mathrm{m} ; \boldsymbol{H}, 30 \mu \mathrm{m}$.
}

"detection call" (Table 2). This suggests that the transcripts of Rab5, Rab4, and Rab11 are expressed when the first RGC axons are extending along the visual pathway. Western blot analysis confirmed the presence of Rab5 and Rab4 in the retinas of stage 33 and 37 Xenopus embryos (data not shown).

Next, we looked at Rab distribution in RGC axons and growth cones using immunocytochemistry and fluorescently tagged proteins. Endogenous Rab5 was detected in the axon shaft and growth cone in whole-eye cultures. Antibody labeling appeared as a combination of diffuse (cytoplasmic) and punctate (vesicle-like) staining, respectively corresponding to the expected distribution of the inactive and active conformation of the Rabs. Rab5-positive vesicle structures were detected in both the peripheral actin-rich domain (red arrowheads) and central, organelle-rich domain (green arrowheads) of the growth cone (Fig. 2A). Similarly, expression of Xenopus Rab5a or Rab5c fused to GFP- or RFP-labeled vesicles in the axons, and both domains of RGC growth cones in vitro (Fig. 2B-D). In the central domain where most of the Rab5 endosomes were found, vesicle diameter was highly variable, suggesting that distinct populations of Rab5-positive endosomes (large and small) coexist. Larger vesicles, which have a dark lumen, were observed only in the central region of the growth cone. In contrast, only small endosomes are found in the peripheral domain, with $75 \%$ of them having an apparent diameter of $<0.6 \mu \mathrm{m}$ (403 particles, $11 \mathrm{GCs}$ ). The distribution of large and small endosomes was found to be similar in growth cones coursing along the optic tact in vivo (Fig. $2 E$ ). This distribution was observed with both Rab5a and Rab5c, and the two proteins colocalized on the same endosomes in the growth cone (data not shown). Rab5c fusions appear to label bona fide early endosomes as they decorate vesicles labeled by the early endosomal marker FYVE-GFP (Fig. 2F; Raiborg et al., 2001; Hayakawa et al., 2007). This distribution is likely to be a general feature of Rab5 endosomes in the growth cone, as it is also observed in growth cones from Xenopus diencephalic neurons (data not shown) and resembled the reported localization of Rab5 in mice cortical neurons (Diestel et al., 2007).

Immunolabeling for endogenous Rab4 was found in axons and growth cones, and showed focal puncta suggestive of vesicular structures in both domains of retinal growth cones (Fig. 2G). Xenopus Rab4-GFP and Rab4-RFP fusion proteins labeled vesicles and short tubules in the axons and throughout the entire growth cone (Fig. $2 \mathrm{H}-\mathrm{J}$ ). As with Rab5 constructs, the diameter of Rab4-labeled vesicles varied, and large vesicles were usually confined to the central region of the growth cone. Although the Rab11 antibody we tested did not cross-react with Xenopus, the GFP-Rab11b fusion protein decorated many small vesicles in the axons and both domains of the growth cone (Fig. $2 \mathrm{~K}$ ). Both Rab4- and Rab11-positive endosomes were found in the peripheral domain, up to the tips of filopodia (Fig. $2 I-K$ ). 

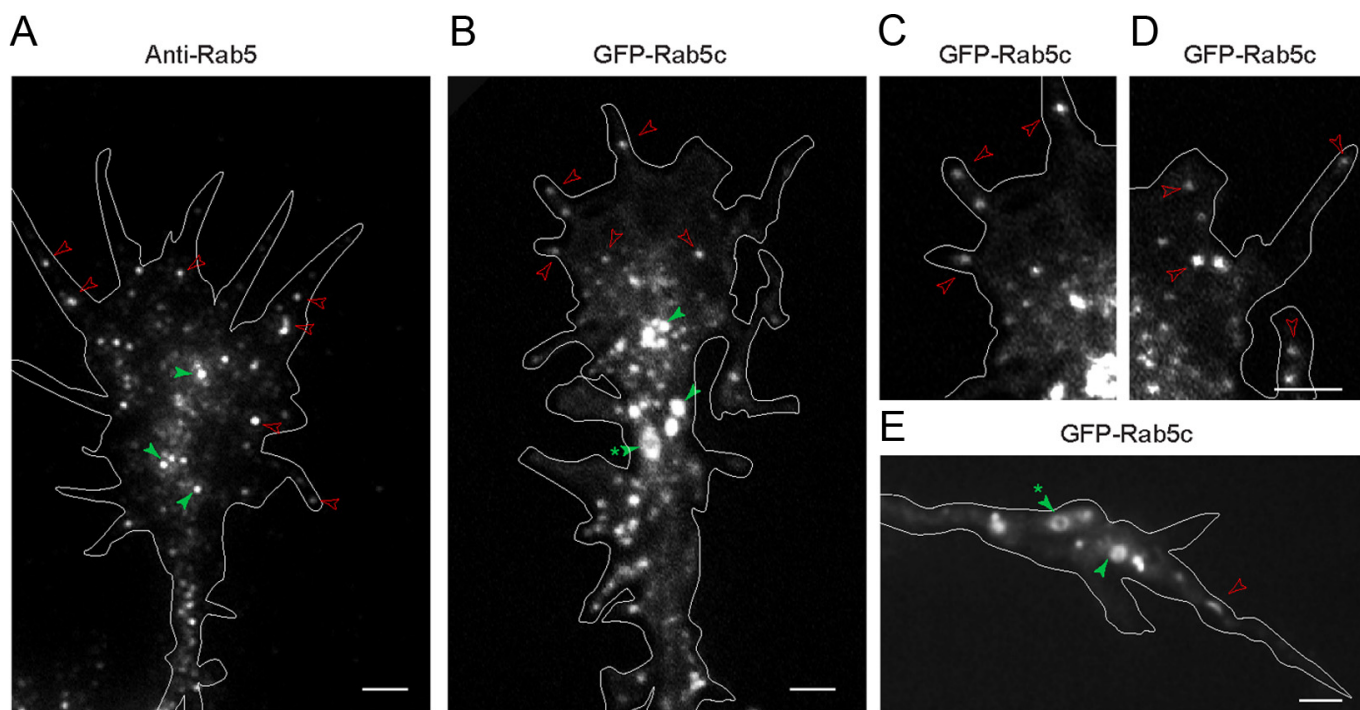

\section{F}
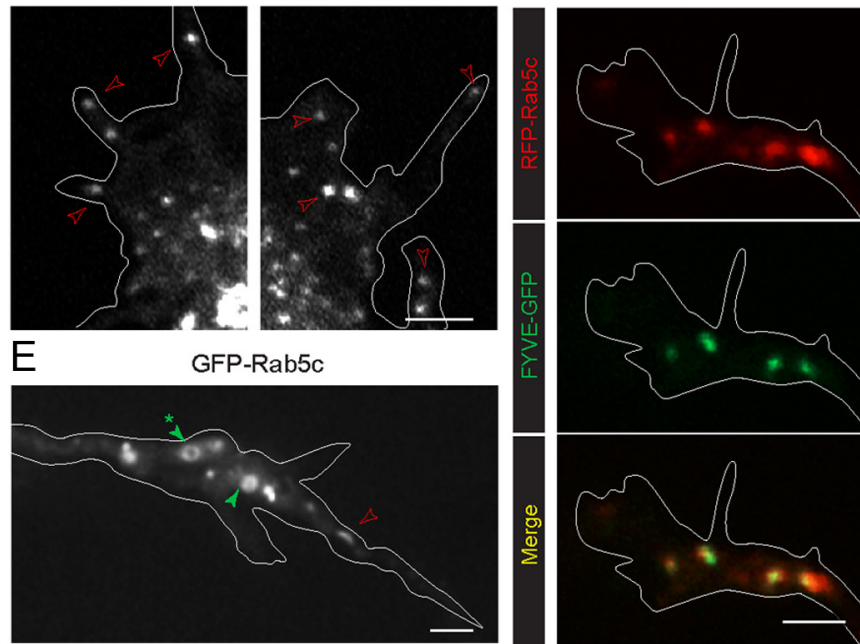

G

$\mathrm{H}$

I

$\mathrm{K}$

GFP-Rab11
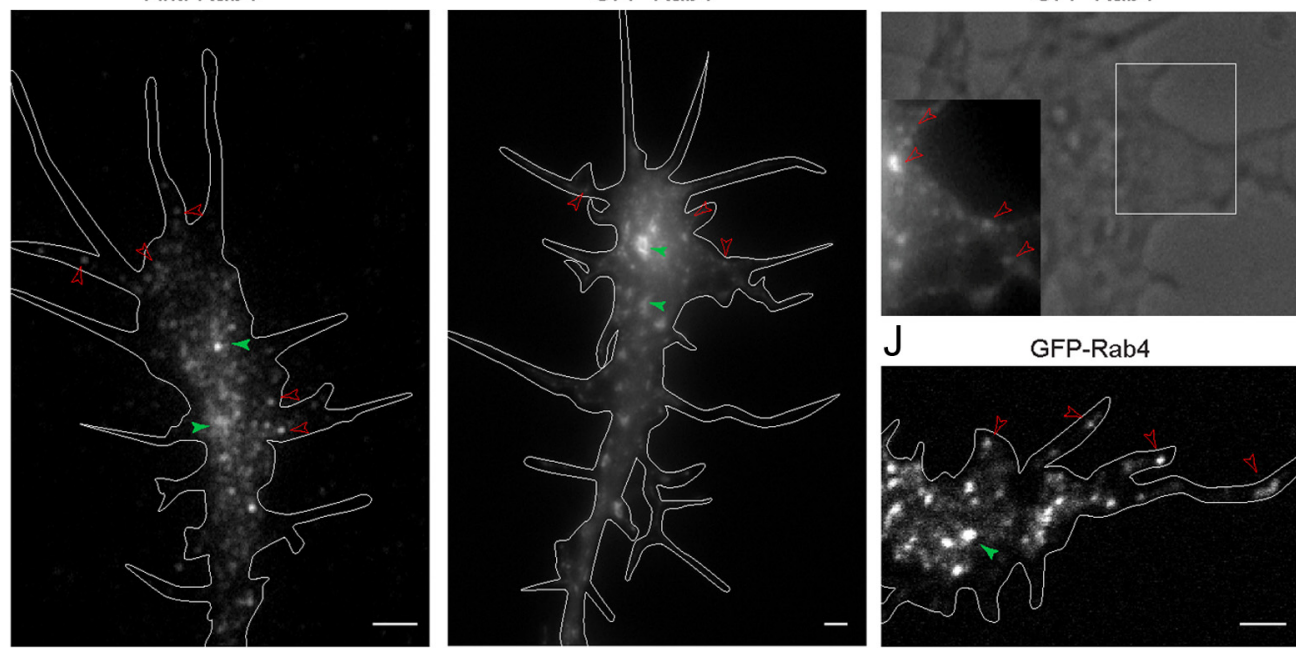

K

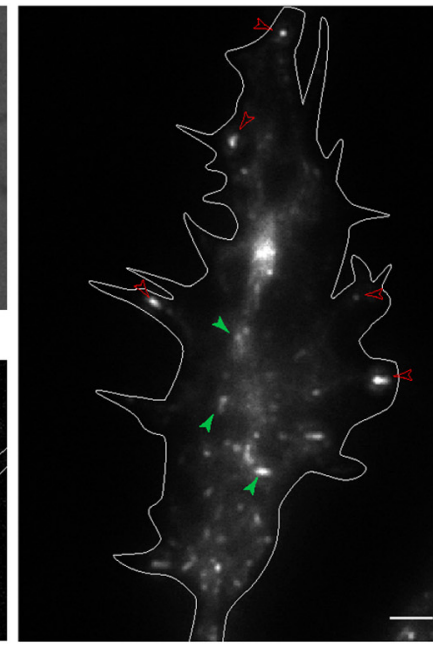

L

M
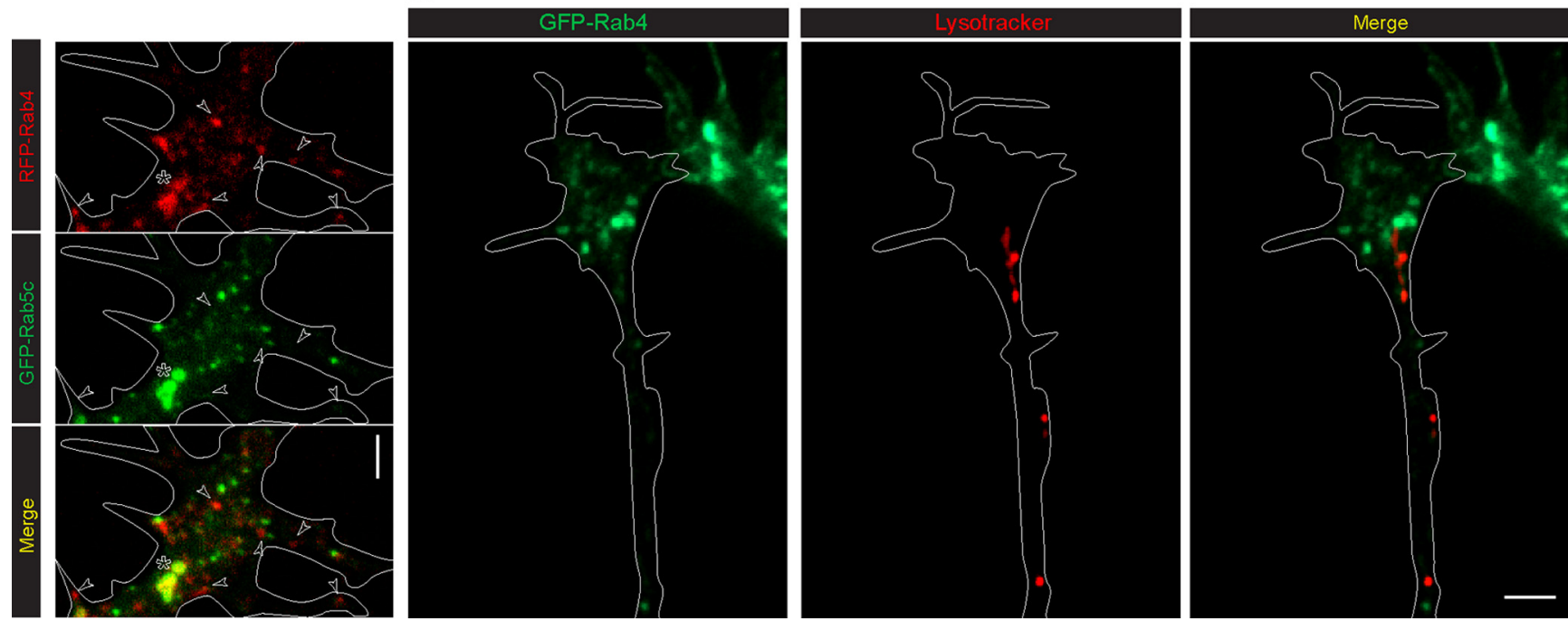

Figure 2. RGC growth cones contain Rab5-, Rab4-, and Rab11-positive endosomes. $\boldsymbol{A}$, Rab5 endogenous protein is detected in axon shaft and growth cone of retinal ganglion cells by immunocytochemistry. Rab5 labeling appears as focal puncta suggestive of vesicles in both the central (filled green arrowheads) and peripheral (open red arrowheads) domains of the growth cone. $\boldsymbol{B}-\boldsymbol{E}$, Xenopus Rab5c fused to GFP labels vesicles in both domains of RGC growth cones in vitro $(\boldsymbol{B}-\boldsymbol{D})$ and in vivo $(\boldsymbol{E})$. $\boldsymbol{C}, \boldsymbol{D}$, Small vesicles are frequently observed in filopodia or lamellipodia. $\boldsymbol{F}$, RFP-Rab5 clabels vesicles that recruit FYVE-GFP (another marker of early endosomes). G, Rab4 is detected in the axon and growth cone of RGCs. Immunoreactivity exhibits vesicular-appearing signals in both domains of the growth cone. $\boldsymbol{H}-\boldsymbol{J}$, Xenopus GFP-Rab4 accumulates on vesicle-like structures present in both domains of the growth cone. I, J, Rab4 vesicles are found in filopodia and lamellipodia. $\boldsymbol{K}$, GFP-Rab11b associates with small vesicles present in the axon shaft and both domains of the growth cone. Filled green and open red arrowheads point (Figure legend continues.) 
In growth cones coexpressing RFP-Rab4 and GFP-Rab5c, Rab4 only colocalized with Rab5c on large vesicles, suggesting that small Rab5-positive endosomes are different from small Rab4-positives ones (Fig. 2L). Colocalization was also partial in growth cones coexpressing Rab11 and Rab5 fusion proteins, suggesting that these Rabs associate with specific endosomes (data not shown), a conclusion strengthened by the fact that the distribution and morphology of Rab7-positive (late) endosomes were different. Rab7-GFP or Rab7-RFP fusions only labeled large vesicles that were confined to central domain (data not shown). Furthermore, Lysotracker, which labels lysosomes, did not stain Rab4- and Rab5c-positive endosomes (Fig. 2M; data not shown). Together, the data suggest that the Rab5, Rab4, and Rab11b selectively label different endosomes that retain characteristics typical of early/sorting and recycling endosomes. Their presence in the growth cone, including the peripheral domain that initiates extension and turning, suggests that they could contribute to axon extension.

Growth cone endosome dynamics: Rab4-positive vesicles may recycle membrane from Rab5-positive endosomes

Previous studies suggested that recycling endosomes, involved in recycling within the growth cone, originate from the endosomes that form in the central domain and then move into the peripheral domain (Kamiguchi and Lemmon, 2000; Kamiguchi and Yoshihara, 2001; Sabo and McAllister, 2003). Thus, we asked, whether Rab4 endosomes that could form within the growth cone central domain could be shipped to the peripheral domain.

Because of the abundance and complex stop-and-start movements of GFP-Rab-labeled vesicles, the contribution of axonally transported endosomes to the growth cone's population is hard to estimate. Thus, to evaluate directly how many endosomes are supplied to the growth cone by the soma, we performed fluorescence recovery after photobleaching (FRAP) experiments (Fig. $3 A$ ). We first examined whether Rab5 endosomes that reappeared in bleached growth cones originated from the axon. FRAP experiments on Rab5c-expressing growth cones showed that less than a quarter of the Rab5c-positive endosomes reappearing in the growth cone could be traced back to the axons $(N=231$ from eight GCs; Fig. 3B,C). This shows that cytoplasmic (inactive) Rab5 can be activated and recruited to endosomal membranes in the growth cone. Rab5 is recruited to long-lasting growth coneresident endosomes (Fig. 3D). However, small short-lived endosomes are also observed during recovery (Fig. $3 D$ ), suggesting that some de novo formation also occurs. This would explain the sudden appearance of Rab5 endosomes that we observed in growth cones having only a few Rab5-positive endosomes. The appearance of new Rab5-positive endosomes is consistent with the presence of Rab5 on clathrin-coated vesicles and macropinocytosomes (Horiuchi et al., 1995; Roberts et al., 2000; Sato et al., 2005; Stenmark, 2009; Feliciano et al., 2011), which could form during basal endocytosis in RGC growth cones. Thus, Rab5 could control locally the biogenesis, stability, and/or movement of the endosomes present in the growth cone.

\section{$\leftarrow$}

(Figure legend continued.) to vesicles located in the central and peripheral domains respectively. $L$, Confocal images of growth cone coexpressing RFP-Rab4 and GFP-Rab5c show that small Rab4-positive endosomes in the periphery are distinct from Rab5 ones (arrowheads). Rab4 and Rab5c colocalize, however, on the large vesicles frequently found in the central domain (asterisk). $\boldsymbol{M}$, Confocal images show that Rab4 endosomes are distinct from the acidic LysoTracker-stained late endosomes and lysosomes. $\boldsymbol{B}, \boldsymbol{F}, \boldsymbol{J}, \boldsymbol{L}$, and $\boldsymbol{M}$ were acquired with a confocal spinning disk. Scale bars: $A-L, 2 \mu \mathrm{m} ; M, 3 \mu \mathrm{m}$.
FRAP of GFP-Rab4 in the growth cone demonstrated that fluorescent Rab4 endosomes could also be recovered independently of axon supply (Fig. 3E), suggesting that Rab4 endosomes can form within the growth cone. In contrast, most of the Rab11b-positive endosomes reappearing in the growth cone could be traced back to the axons (nine GCs; Fig. 3F). Thus, like Rab5, Rab4 is also activated locally and could regulate formation of membrane-bound carriers within the growth cone. In cell lines, Rab4 endosomes bud off Rab5-positive endosomes (Sönnichsen et al., 2000; Rink et al., 2005). Using fast image capture (two frames per second) on growth cones expressing both GFPRab5 and RFP-Rab4, we observed Rab4-positive vesicles splitting from Rab4-positive tubules that emanate from vesicles positive for both Rab5c and Rab4 (Fig. 4A). Interestingly, after photobleaching Rab4 was recovered onto large Rab5-positive endosomes in the growth cone (Fig. 4B). Thus, part of the small Rab4positive endosomes that are detected during FRAP experiments could originate from the Rab5c-positive sorting endosomes present in the growth cone.

Next, we asked whether the Rab4-positive endosomes could be shipped from the central to the peripheral domain. Photobleaching of the growth cone's peripheral domain showed that there is a net export of Rab4-positive endosomes from the central domain (Fig. 4C). Consistent with this, tracking of individual Rab4 endosomes demonstrated that they move within the peripheral domain along the filopodia (Fig. 4D). Thus, Rab4positive endosomes could mediate the centrifugal transport of recycled proteins.

Finally, we tested whether recycled surface proteins transit through Rab4 endosomes. Cleavable biotin was allowed to internalize in growth cones expressing either GFP-Rab5c or GFPRab4. Internalized biotin was found in a subpopulation of both Rab5- and Rab4-positive endosomes (Fig. 4E; data not shown). In GFP-Rab4-expressing growth cones, biotin was even observed in small Rab4-positive endosomes present in growth cone filopodia (Fig. 4F). Similarly, immediately after FM4-64 loading, examples of dye-loaded GFP-Rab4-positive vesicles were observed mainly in the peripheral domain including filopodia (data not shown). Together, our data indicate that constitutively internalized surface proteins transit via Rab5 and Rab4 endosomes during their recycling.

Altogether, our results suggest that Rab4 could, indeed, participate in recycling membrane from the Rab5-positive endosomes in the growth cone. Rab4 could be recruited to Rab5positive endosomes present in the growth cone. Then, Rab4 domains could bud off to form small vesicles that can be shipped to the peripheral domain. As local dynamics of endosomes labeled by Rab5 and Rab4 fusion fit with the predicted dynamics of endosomes needed for local recycling (Kamiguchi and Lemmon, 2000), these proteins might be important for morphological remodeling and growth cone advance.

\section{Constitutively active Rab5 impairs axon extension in vitro}

Rab5 and Rab4 dynamics suggest that they partake in the primaquine-sensitive recycling that regulates RGC axon elongation in vitro. This hypothesis is supported by reports indicating that the effects of primaquine and calmodulin inhibition (that primaquine could induce) are reminiscent of the ones induced by the constitutively active (CA) form of Rab5 (Stoorvogel et al., 1987; van Weert et al., 2000; Tebar et al., 2002). Indeed, CARab5c expression blocks recycling and similarly leads to intracellular accumulation of receptors in enlarged sorting endosomes (Stenmark et al., 1994; Ullrich et al., 1996; Leterrier et al., 2004). 
A

Pre-bleaching

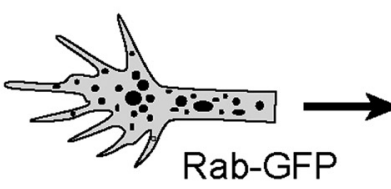

B

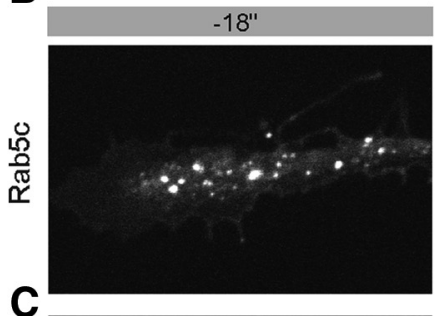

C

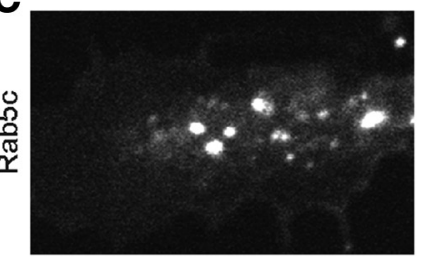

D
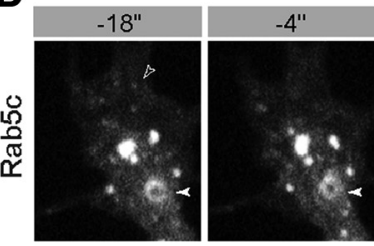

E

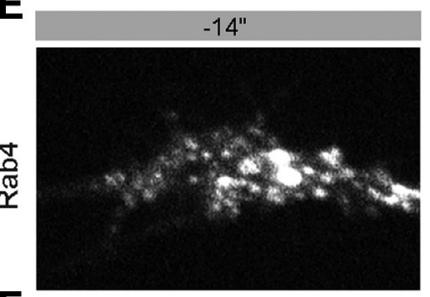

F

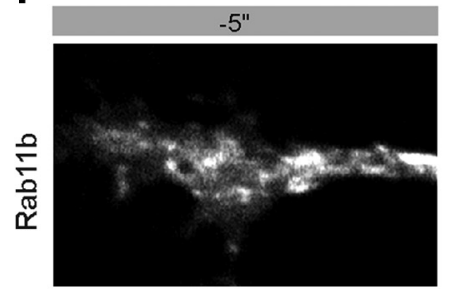

photobleaching

$0^{\prime \prime}$
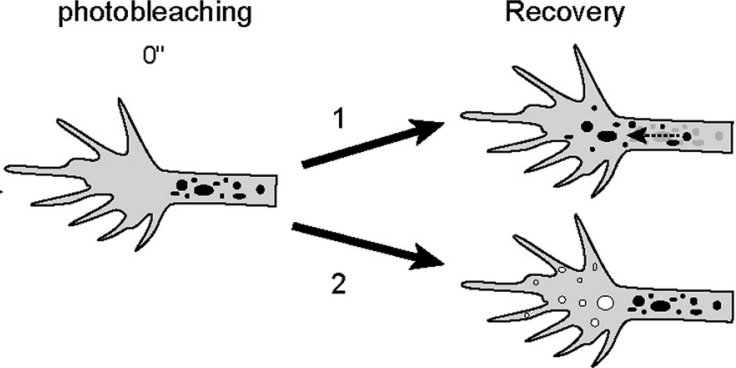
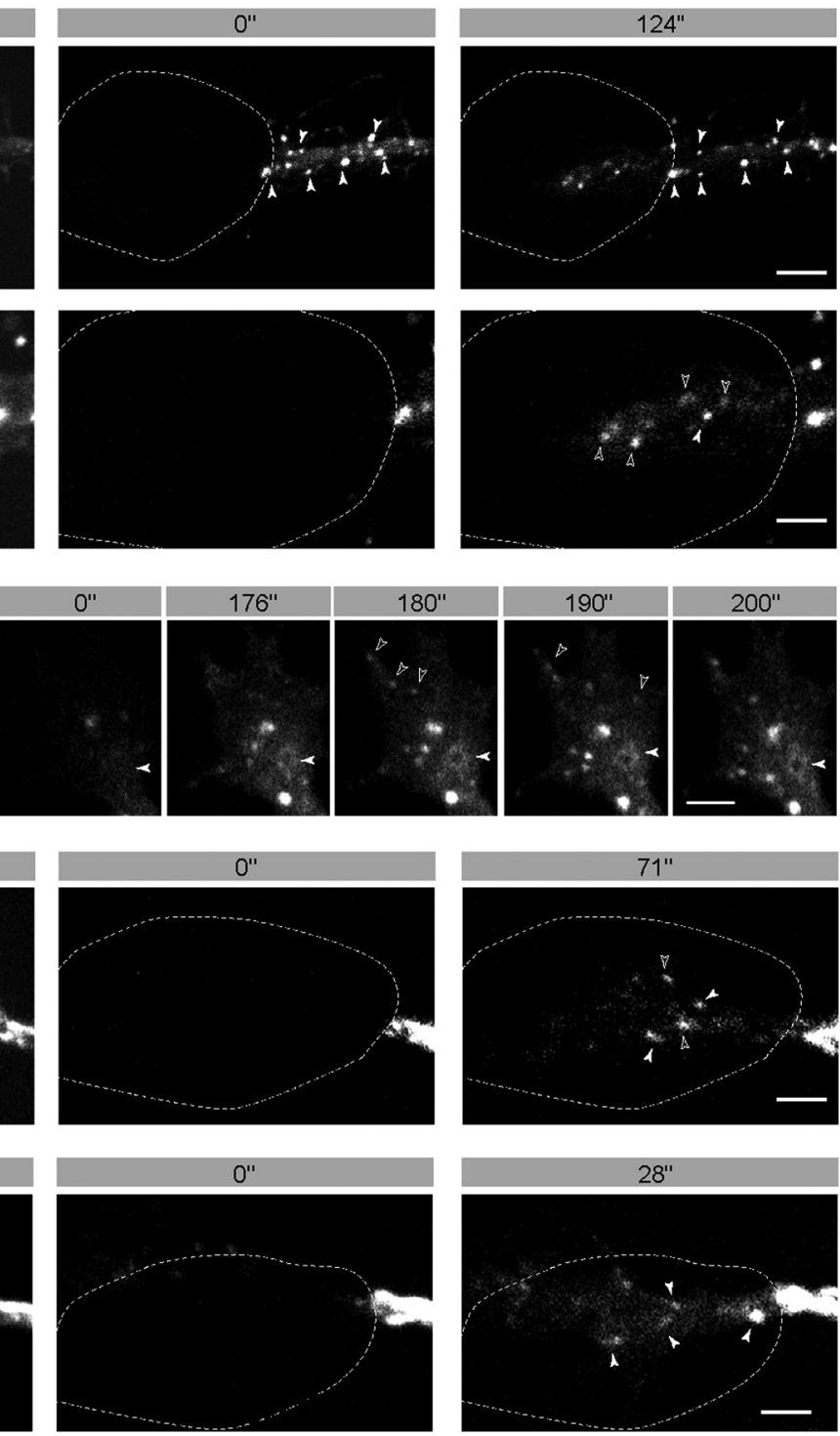

Figure 3. FRAP analysis indicates that Rab5- and Rab4-positive endosomes could form locally. $\boldsymbol{A}$, The schematic illustrates the use of FRAP to define the origin of the Rab-positive endosomes present in the growth cone. The GFP-positive endosomes that reappear after photobleaching can be (1) unbleached endosomes that moved from the axon or (2) endosomes that have recruited unbleached cytosolic Rab5c-GFP that diffused into the growth cone. $\boldsymbol{B}-\boldsymbol{F}$, Representative images of the GFP signal before bleaching, immediately after, and during the recovery in growth cone expressing GFP-Rab5c (B-D), GFP-Rab4 (E), or GFP-Rab11 (F). B, Rab5c-positive endosomes have reappeared in the bleached growth cone, although many of the axonal Rab5c-positive endosomes remained in the axon (white arrowheads). C, Tracking of the endosomes present in the growth cone suggests that the majority of the Rab5c-positive endosomes does not come from the axons as only one of five endosomes labeled could be traced back to the axon. $\boldsymbol{D}$, Rab5 signal is recovered on both long-lasting large endosomes and small dynamic endosomes. The small endosomes in the lamellipodia (open arrowhead at $-18 \mathrm{~s}$ ) move or disappear within $10 \mathrm{~s}$. In contrast, large endosomes (filled arrowhead) remain stable and show little displacement. During the recovery, the large endosomes progressively recover Rab5 signal (filled arrowhead). In addition, small endosomes appear suddenly in the peripheral domain (open arrowheads at 180 and 190 s). $\boldsymbol{E}$, Still images illustrating the GFP-Rab4 signal during the FRAP experiment. As with GFP-Rab5, GFP-Rab4 signal is recovered in the growth cone. Similarly, many Rab4-positive endosomes that appear in the growth cone after photobleaching could not be related to axonal endosomes $(\boldsymbol{E})$. In contrast, most of the Rab11-positive endosomes come from the axon ( $\boldsymbol{F}$ ). Open arrowheads identify endosomes that appear to have formed within the growth cone. Filled arrowheads point to the endosomes that have moved from the axon. Dotted lines outline the bleached area. "denotes seconds $S$ cale bars: $\boldsymbol{A}, \boldsymbol{C}-\boldsymbol{F}, 2 \mu \mathrm{m} ; \boldsymbol{B}, 4 \mu \mathrm{m}$. 
To directly test the hypothesis that Rabs may regulate axon elongation, we impaired their activities and monitored in vitro the extension rate of RGC axons. Since previous studies reported difficulty using a knock-down approach to block recycling (Deneka et al., 2003; Chen et al., 2009; Grant and Donaldson, 2009; Zeigerer et al., 2012), we initially chose to use Rab5 and Rab4 mutant proteins.

Thus, we generated a point mutation in the Xenopus GFP-Rab5c corresponding to the previously described Q79L mutation that blocks GTPase activity of Rab5 and locks it in its active form (Stenmark et al., 1994). Xenopus CA-Rab5c marked unusually large endosomes in transfected RGC somata, demonstrating that our construct has a CA activity (Fig. 5A). Eyes from the embryos electroporated with GFP- or CA-Rab5c were cultured overnight in basal medium on polylysine/ laminin substrata, and the elongation rate was measured by time-lapse recording. The extension rate of GFP-expressing axons was $35 \pm 1.4 \mu \mathrm{m} / \mathrm{h}(N=400)$, a value close to that previously reported for RGC axons in vitro (McFarlane et al., 1996). Consistent with the effect of primaquine, the extension rate of axons expressing $\mathrm{Xe}$ nopus CA-Rab5c dropped by $33 \%$. Expression of the previously characterized zebrafish CA-Rab5c (Ulrich et al., 2005) decreased the extension rate of axons by $51 \%$, confirming the result obtained with the mutant Xenopus protein (Fig. 5B-D).

Although the axon lacks giant endosomes, possibly because some Rab5 effectors are missing (Wilson et al., 2000; Deinhardt et al., 2006), the expression of CA-Rab5c altered the apparent size and dynamics of endosomes in GCs. We found that the apparent mean diameter increased in CA-Rab5-expressing growth cones (Fig. 5E; Wt-Rab5: $0.45 \pm 0.01 \mu \mathrm{m}$, $N=404$ particles; CA-Rab5c: $0.60 \pm 0.03$ $\left.\mu \mathrm{m}, N=64 ; p=7.7 \times 10^{-6}\right)$. Although the change in Rab5 density on endosomes could affect our measurements, the apparent enlargement of endosomes that we observe in CA-Rab5-expressing axons is consistent with previously published electron microscopic data (de Hoop et al., 1994). Interestingly, the increase in endosome size correlates with a decrease in the fraction of endosomes present in the peripheral domain (Wt-Rab5: $36.7 \pm 3.8 \%, N=22$ growth cones; CA-Rab5c: $15.7 \pm 7.4 \%, N=$ 5 growth cones; $p=0.025$, Mann-Whitney test). The maximal diameter was unchanged, but the smaller endosomes were completely absent from growth cones expressing CA-Rab5. FRAP experiments revealed that, unlike the wild-type Rab5c-positive endosomes, the majority (75\%) of CA-Rab5c-positive endosomes repopulating the few bleached growth cones that exhibited a recovery originate from the axons (three of eight growth cones;

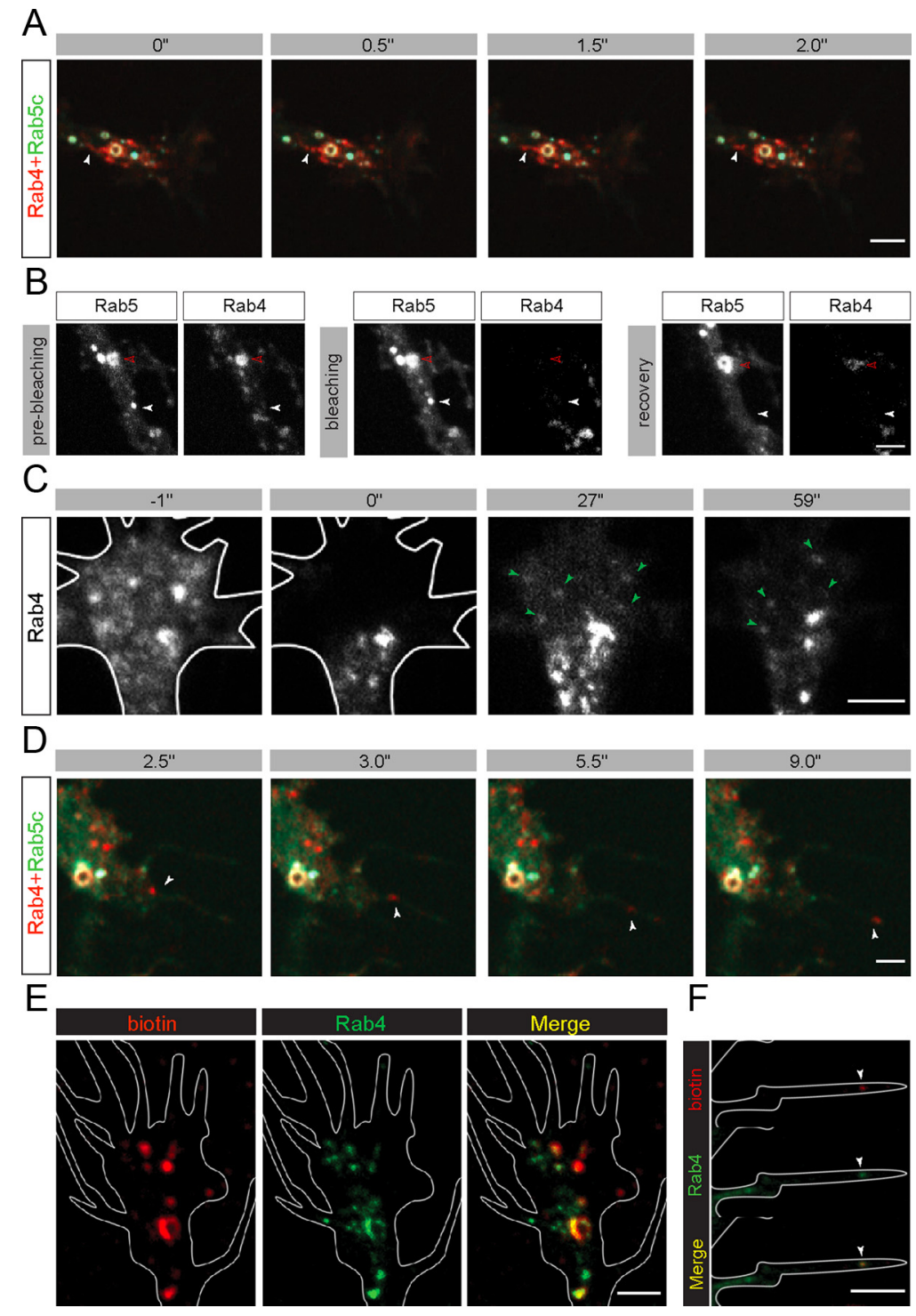

Figure 4. Dynamic analysis of Rab4-positive endosomes suggests that they support local recycling in the growth cone. $\boldsymbol{A}$, Time-lapse confocal images show a Rab4-positive tubule (arrowhead) that buds and splits from a large Rab5c-and Rab4-positive endosome. The $2 \mathrm{~Hz}$ time-lapse imaging was performed on growth cones coexpressing wild-type Xenopus GFP-Rab5c and RFPRab4. B, After photobleaching, the RFP-Rab4 signal recovers on large GFP-Rab5c-positive endosomes in RGC growth cone. Left, Prebleaching signal ( $-4 \mathrm{~s})$. Middle, The RFP signal, but not the GFP signal, is lost after photobleaching (0s). As illustrated in the left panel (150s), during recovery, the RFP signal is progressively recovered on the large GFP-positive endosome (red arrowhead). Rab4 is not recruited to Rab5 endosomes that were Rab4-negative (white arrowhead). C, Bleaching of the peripheral domain reveals the shipment of small Rab4-positive endosomes from the central to the peripheral domain (green arrowheads). $\boldsymbol{D}$, Time-lapse images illustrate the entry of a small Rab4-positive (Rab5-negative) endosome into a filopodium and its movement toward the tip. Arrowheads mark the position of the endosome at different time points. $E, F$, Confocal images show that internalized biotinylated proteins (red) partially colocalize with vesicles labeled by GFP-Rab4 (green). The small Rab4-positive endosomes present in filopodia also contain biotinylated proteins (arrowhead, $\boldsymbol{F}$ ). " denotes seconds. Scale bars, $2 \mu \mathrm{m}$.

WT-Rab5c: $18.4 \pm 4.4 \%$, nine growth cones; CA-Rab5c: $74.7 \pm$ $3.2, N=3$ growth cones; $p=0.0158$, Mann-Whitney test). Thus, part of the growth inhibition induced by Rab5c is likely to be due to impaired local trafficking within the growth cone.

\section{Rab4-dependent traffic is altered by primaquine and CA-}

Rab5c, and contributes to axon extension

In non-neuronal cell lines, both primaquine and CA-Rab5c were shown to block Rab4-dependent recycling (Capps and Zúñiga, 2000; Roberts et al., 2001; Leterrier et al., 2004; Jones et al., 2009). In addition, we found that during primaquine treatment, GFPRab4 disappeared from the small vesico-tubular organelles to 

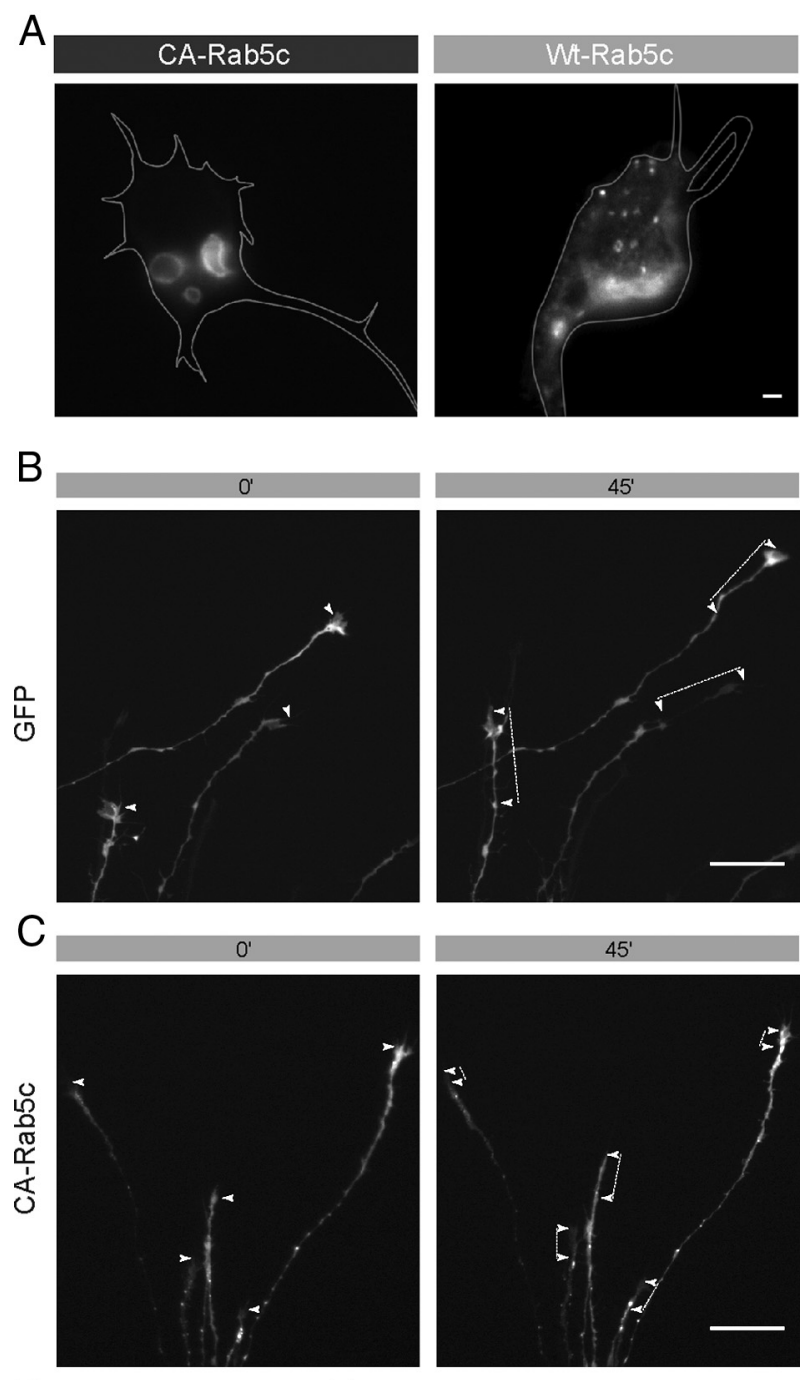

D

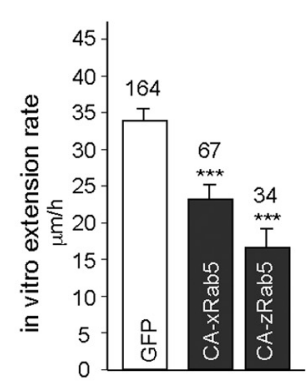

$\mathrm{E}$

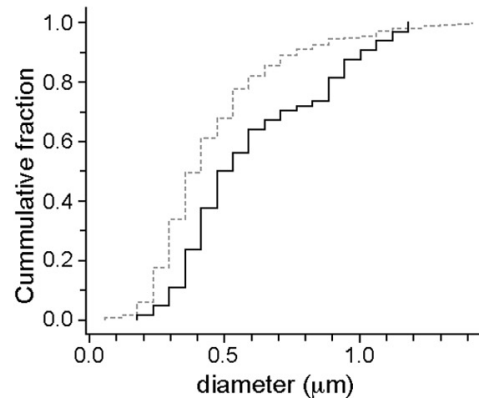

Figure 5. Constitutively active Rab5 slows the axon extension rate in vitro. $\boldsymbol{A}$, The electroporation of CA-Rab5c in RGCs induces the formation of enlarged endosomes. In the RGC soma, CA-Rab5c that lacks GTPase activity (QL mutant) labels endosomes that are considerably larger than those labeled by wild-type GFP-Rab5c. B, C, Still images from time-lapse sequences illustrate axon extension of GFPexpressing $(\boldsymbol{B})$ and constitutively active GFP-Rab5c-expressing $(\boldsymbol{C})$ axons. Time-lapse imaging was performed on whole eyes from stage 33/34 embryos that had been cultured overnight. Arrowheads indicate the positions of the growth cone at 0 and $45 \mathrm{~min}$. Dotted lines exemplify the distance extended by the growth cones during the $45 \mathrm{~min}$ recording period. $\boldsymbol{D}$, The histogram shows the average extension rate of axons expressing GFP, the Xenopus CA-Rab5c we generated (xRab5QL), and the previously characterized zebrafish CA-Rab5c (zRab5c) constructs. $E$, Cumulative distributions of the apparent diameter of the endosomes labeled by GFP-CA-Rab5c (black line; $N=64$ ) and wild-type GFP-Rab5c (gray dotted line; $N=404$ ) suggest that the CA-Rab5c leads to an enlargement of the Rab5-positive endosomes in the growth cone. Numbers above the bars indicate the number of axons analyzed. Error bars represent the SEM. ${ }^{* *} p<0.001$ vs the control (GFP). ' denotes minutes. Scale bars: $\boldsymbol{A}, 2 \mu \mathrm{m} ; \boldsymbol{B}, \boldsymbol{C}, 30 \mu \mathrm{m}$. accumulate on unusually large vesicles and long tubules (Fig. 6A). In growth cones expressing CA-Rab5c, we noticed that the number of RFP-Rab4-positive endosomes was decreased in axons and growth cones (GFP: $1.2 \pm 0.07$ endosomes $/ \mu \mathrm{m}^{2}, N=58$; GFPCA-Rab5c: $0.67 \pm 0.04$ endosomes $/ \mu \mathrm{m}^{2}, N=56 ; p=2.8 \times$ $\left.10^{-10}\right)$. These results suggest that Rab4-dependent traffic in the growth cone is altered both by primaquine treatment and CARab5c expression. Thus, we tested whether axon elongation depends on Rab4.

Rab4 protein sequences from mouse and Xenopus align well. Consequently, we introduced the described Q67L and N121I amino acid changes to create, respectively, CA and DN forms of Rab4 (Cormont et al., 1996; Roberts et al., 2001; Leterrier et al., 2004; White et al., 2007; Witze et al., 2008). In contrast to wild type, DN-Rab4 did not have a punctate distribution in growth cone (Fig. $6 B$ ). We measured the extension rate of RGC axons expressing GFP, CA-Rab4, and DN-Rab4 from time-lapse movies. We found that DN-Rab4 expression slowed down axon elongation in vitro by $25 \%$ (Fig. $6 C-E$ ). In contrast, the axon elongation rate was the same in axons expressing GFP and CARab4 mutant, which should not impair Rab4-dependent recycling (Leterrier et al., 2004) (Fig. 6E). This showed that Rab4 is, indeed, required for axon growth.

To demonstrate that growth inhibition is not due to impaired lysosomal degradation potentially induced by Rab5 and Rab4 (McCaffrey et al., 2001; Chen et al., 2009), we checked whether by selectively impairing degradation with Rab7 mutants we could block axon growth. We electroporated Xenopus with GFP-Rab7 bearing the mutations corresponding to the T22N and Q67L. These transformations have been extensively used as DN- and CA-Rab7, respectively (Mukhopadhyay et al., 1997; Bucci et al., 2000). Time-lapse monitoring of DN- or CA-Rab7a transfected axons revealed no change in axon elongation rate (Fig. $6 F$ ). Similarly, expression of the previously characterized mammalian DN-Rab7 had no effect on axon elongation in vitro (Fig. 6F). Thus, CA-Rab5c and DN-Rab4 may act primarily by impairing recycling.

Since the inhibition of short-loop recycling was also observed after Rab4 depletion (Jones et al., 2009), we performed morpholino-induced knockdown of Rab4. An injection of 12 ng of antisense MO against Rab4 resulted in a 50\% knockdown Rab4 protein and had no obvious deleterious effects on embryo development (Fig. 7A-C). Specifically, the Rab4 fluorescent signal decreased significantly from $21.5 \pm 3$ A.U. $(N=$ 10) in control-MO-loaded RGC growth cones to $10.7 \pm 1.3$ A.U. $(N=11 ; p=0.003)$ in Rab4-MO-loaded growth cones (Fig. 7C). Monitoring of MO-loaded axons showed that axon elongation drops by $25 \%$ when Rab4 is depleted (control MO: $51.7 \pm 3.2 \mu \mathrm{m} / \mathrm{h}, N=62$; Rab4 MO: $38.6 \pm 2.5 \mu \mathrm{m} / \mathrm{h}, N=70$; $p=5.2 \times 10^{-6}$; Fig. $\left.7 D, E\right)$. Altogether, this suggests that Rab4-dependent recycling appears to be crucial for RGC axon elongation in vitro.

\section{Constitutively active Rab5c and dominant-negative Rab4 delay axon arrival at the tectum}

To test whether Rab4 and Rab5 control axon elongation in vivo, we analyzed the timing of axon arrival at the tectum. Instead of microinjection, which might interfere with Rab5 (and Rab4) functions during early embryogenesis, we opted for eye-targeted electroporation at the stage when the first RGCs are born (i.e., stages 26-28; Fig. 8A). Detectable expression is expected to start after $6 \mathrm{~h}$, thus, at the stage when axons have initiated their elongation in the retina (Falk et al., 2007). Robust expression 
of the different constructs was consistently observed in the eye $14 \mathrm{~h}$ postelectroporation, indicating that high levels of expression were attained by the time the axons navigated into the optic pathway.

We analyzed the length of transfected axons in brains from stage $37 / 38$ and $39 \mathrm{em}$ bryos (Fig. $8 B$ ) when axons first reach the tectum (Holt and Harris, 1983; Holt, 1984). At stage 37/38, control GFP-labeled axons were already extending in the brain up to the diencephalic turn, and some were already approaching the anterior tectum boundary (Fig. 8C). Six hours later, at stage 39, control GFP-labeled axons had reached the tectum and were coursing toward its dorsal and/or caudal regions. Of particular note, axons expressing the Rab4, Rab5, or Rab7 mutants coursed apparently normally along the optic tract without exhibiting pathfinding errors at any of the stages analyzed and reached the tectum by stage $40(N>20$ embryos per condition). Despite lacking guidance defects, however, CA-Rab5- or DN-Rab4expressing axons appeared shorter than control GFP-expressing axons. In the most extreme cases, no axons could be seen in the optic tract at stage $37 / 38$, although transfected axons could be seen in the optic nerve. We quantified the average length of the longest (stage 37/38) or the three longest (stage 39) GFP-positive axons expressing GFP, the constitutively active GFP-Rab5c or GFP-Rab4 mutants. Axons expressing the Xenopus CA-Rab5c and the zebrafish CARab5c were significantly shorter than the axons expressing GFP at both stage 37/38 and stage 39 (Fig. $8 D, E$ ). Consistently, axon length decreased by $62 \%$ when we measured the axon length based on the RFP we coelectroporated with GFP or CA-Rab5c, ruling out an effect of detection bias on the measurements $(N=9 \mathrm{GFP}+\mathrm{RFP}, N=12$ GFP+CA-Rab5c). Axons expressing the DN-Rab4 were also significantly shorter than controls at all stages analyzed (Fig. $9 B, D, E)$. In contrast, the expression of CARab4 mutant did not delay axon arrival at the tectum (Fig. 9C-E). In addition, DNRab7-expressing axons were not significantly shorter than control axons at any of the stages analyzed (Fig. 9F). Because the kinetics and levels of expression appeared approximately similar for all constructs, the decrease in axon length appears to correlate specifically with their ability to block recycling.

A delay during the RGC differentiation and axon initiation could lead to axon shortening just as much as a decrease in axon elongation rate. To test whether the slower rate of axon elongation we observed in vitro is relevant to the in vivo phenotype, we measured the elongation speed of transfected axons growing along the optic tract in live Xenopus brain. In vivo time-lapse imaging of RGC axons showed that axons expressing DN-GFP-

C $\quad 0 \min$

E
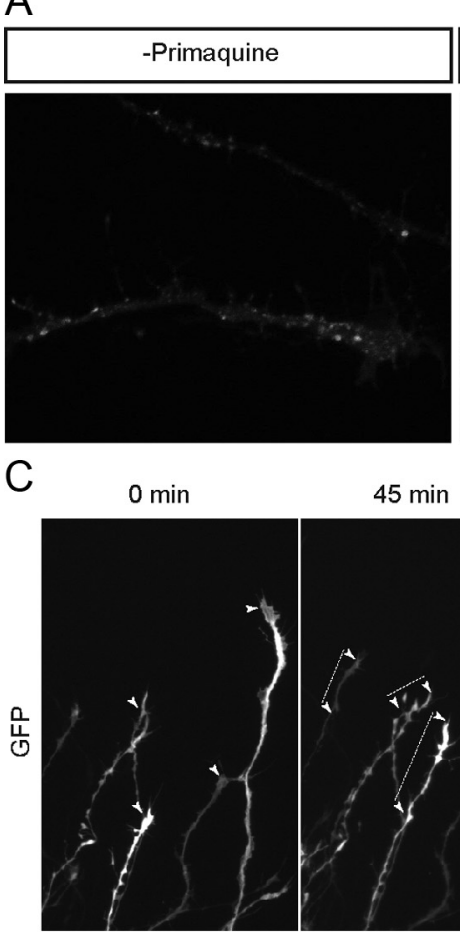

$45 \min$

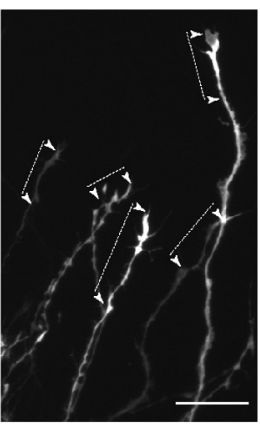

Figure 6. Dominant-negative Rab4 slows the axon extension rate in vitro. A, Primaquine treatment alters Rab4-positive endosomes. Images of Rab4-expressing axons before (left) and $45 \mathrm{~min}$ after (right) primaquine application (0.05 mm) illustrate the appearance of large abnormal Rab4-positive tubules (arrowheads). $\boldsymbol{B}$, An example of RGC growth cone expressing the dominantnegative Xenopus GFP-tagged Rab4-NI mutant. Note that, in contrast to wild type ( $\boldsymbol{A}$, left), the mutant does not display a punctate distribution. $\boldsymbol{C}-\boldsymbol{E}$, DN-Rab4 construct impairs axon extension. $\boldsymbol{C}, \boldsymbol{D}$, Images of GFP-positive axons at the start and the end of the positions of the growth cones at 0 and $45 \mathrm{~min}$. Dotted lines highlight the distance extended by the growth cones during this period. $\boldsymbol{E}$, The histograms show the average extension rate measured from time-lapse recording of axons that expressed GFP, DN-xRab4 expressed DN-Rab7 (TN mutation) or CA-Rab7 (QL mutation) was measured from time-lapse recording and compared with the extension rate of GFP-expressing axons from the same electroporation batch. Neither Xenopus (xRab7) nor human (hRab7) DNRab7 decreases the axon extension rate. Numbers above the bars indicate the number of axons $(\boldsymbol{E}, \boldsymbol{F})$. Error bars represent the $S E M$. ${ }^{* * *} p<0.001$ vs the control. Scale bars: $A, B, 5 \mu \mathrm{m} ; C, D, 30 \mu \mathrm{m}$.

Rab4 extended at half the speed of control axons within the optic tract (Fig. 9G,H). Thus, the decrease in axon length observed in vivo is likely to be due, at least in part, to slower progression of RGC axons along their path.

\section{Discussion}

In the present study, we demonstrate that in the Xenopus visual system interfering with either Rab5c or Rab4 function hampers axon elongation in vitro and in vivo. Based on our in vitro imaging, we propose that Rab4-positive endosomes mediate recycling from the Rab5 sorting endosomes in the growth cone and thereby contribute to the local recycling that aids axon growth. 
A

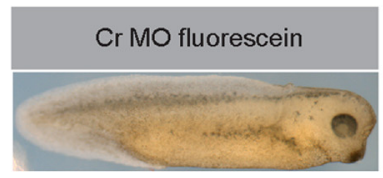

Rab4 MO fluorescein

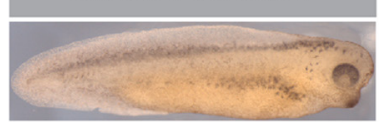

B

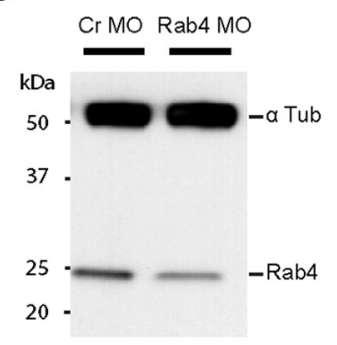

C

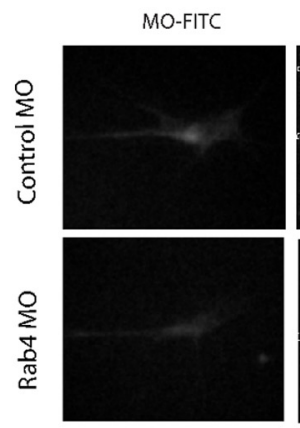

E
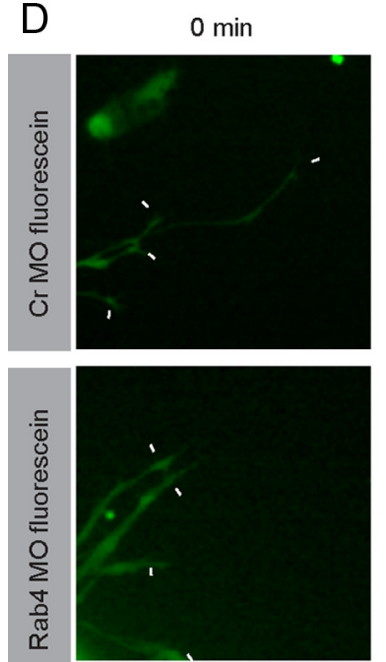

$45 \min$
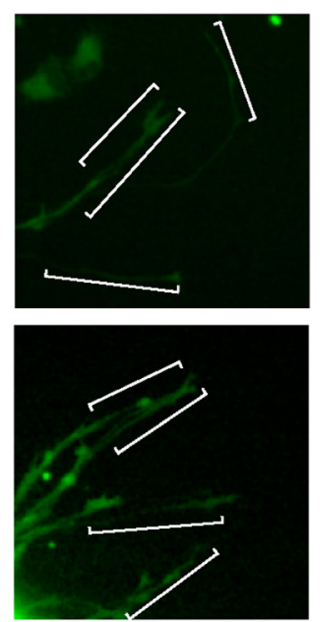

$45 \mathrm{~min}$
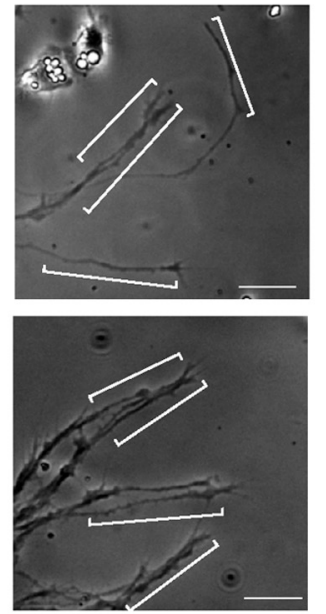

Rab4 IF
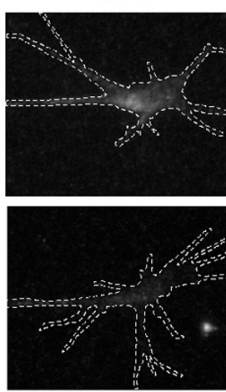

Actin (phalloidin)
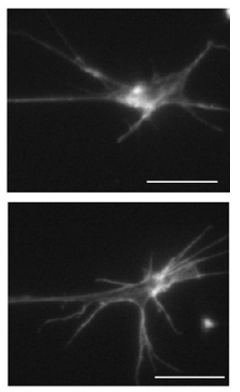

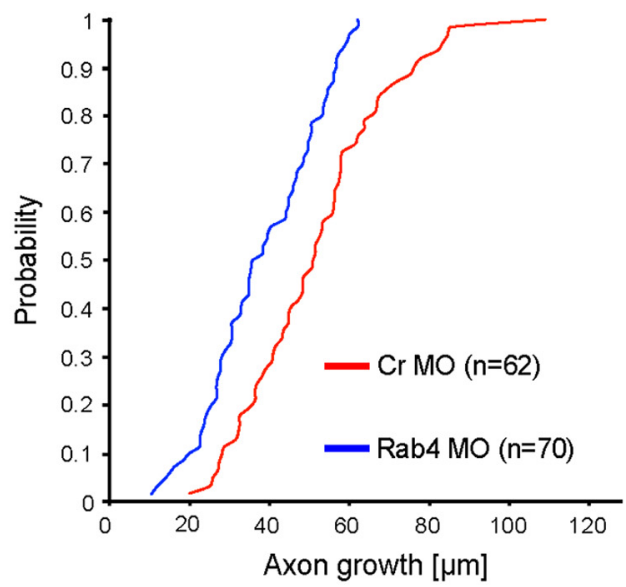

Figure 7. Rab4 knockdown impairs axon elongation in vitro. $A$, The assessment of the effect of Rab4 morpholino on developing Xenopus embryos. Shown are typical examples of embryos at stage 33-34, injected with $12 \mathrm{ng} /$ blastomere fluorescein-tagged control morpholino (top) or Rab4 morpholino (bottom). Note that, at this dose, the Rab4 morpholino does not cause any gross developmental abnormalities. $\boldsymbol{B}$, Rab4 morpholino reduces the Rab4 protein levels approximately by half. Shown is a representative example of a Western blot of brain-and-eye protein extracts from stage 37 embryos. C, Rab4 morpholino reduces the levels of Rab4 protein in RGC growth cones of cultured eye explants by $50.1 \pm 6.2 \%$ relative to control morpholino. All quantified growth cones contain green fluorescence from the morpholino tag. Actin (phalloidin) staining was used to show the outline of the growth cone. $\boldsymbol{D}$, Rab4 morpholino impairs axonal outgrowth in vitro. The extension of axons containing either control morpholino (green, top row) or Rab4 morpholino (green, bottom row) was monitored over 45 min. Corresponding phase-contrast images (grayscale) were used for actual measurements. Scale bars: $\boldsymbol{C}, 10 \mu \mathrm{m}, \boldsymbol{D}, 25 \mu \mathrm{m}$. $\boldsymbol{E}$, Quantification of $\boldsymbol{D}$. Axon outgrowth is significantly reduced in cells containing Rab4 morpholino. Cumulative distribution plots show that both datasets: control morpholino (red line) and Rab4 morpholino (blue line) are significantly different from each other $\left(p=5.15 \times 10^{-6}\right.$, Student's $t$ test).

\section{Rab5 and Rab4 contribute to local recycling within the growth cone}

Our data suggest that the primary function of Rab5 and Rab4 is to control local recycling during axon elongation. Indeed, blockade of the late endosome/lysosome pathway does not inhibit axon elongation, while pharmacological inhibition of Rab4-depedent recycling does. We show that Rab4 and Rab5 proteins are found in growth cones where they can be activated and recruited to endosomes, as demonstrated by FRAP experiments. Importantly, pharmacological treatment known to block Rab4-dependent recycling (Roberts et al., 2001; Jones et al., 2009) perturbed Rab4 endosome morphology in RGC axons and inhibited within minutes constitutive recycling in the growth cone. In agreement with observations in cell lines (Sönnichsen et al., 2000), we found that Rab4 accumulates on tubules that protrude from Rab5 endosomes and then split into vesicles. This suggests that, in growth cones, Rab4 may control budding of recycling vesicles and cargo transfer from early endosomes to recycling endosomes as it does in other cell types (Chavrier et al., 1997; Pagano et al., 2004). Rab4 also controls endosome motility (Bananis et al., 2003) and could therefore regulate the transport of recycling vesicles within the growth cone. In agreement with this, we found that Rab4-positive vesicles move into the peripheral domain of growth cones and that peripherally located Rab4 vesicles contain recycling molecules (biotin, FM dye). We observed Rab4 endosomes moving from the central regions and disappearing on reaching the growth cone periphery. Although suggestive of Rab4-positive vesicle fusion with the plasma membrane, this result cannot be taken as definitive proof.

The morpholino knockdown and mutant data link Rab4 to recycling, but a direct role in exocytosis has not been shown. On the contrary, during $\mathrm{Fc}$ receptor recycling in an endothelial cell line, Rab4 is lost before vesicles fuse with the plasma membrane (Ward et al., 2005). DN-Rab4 has been shown to prevent membrane reinsertion of receptors in neurons (Li et al., 2012), potentially linking Rab4 to exocytosis, but whether this also occurs in RGC growth cones remains to be demonstrated. Nevertheless, the proposed role of Rab5 and Rab4 in controlling the return of recycled material to the membrane fits well with other observations. Constitutive bulk recycling of the membrane in motile growth cones involves large endosomes positive for a Rab5 effector (Schnatwinkel et al., 2004; Bonanomi et al., 2008). Moreover, the recycling of several adhesion molecules that could support outgrowth depends on Rab5 and Rab4 in other models (Strachan and Condic, 2004; Panicker et al., 2006; Diestel et al., 2007; White et al., 2007). 
A

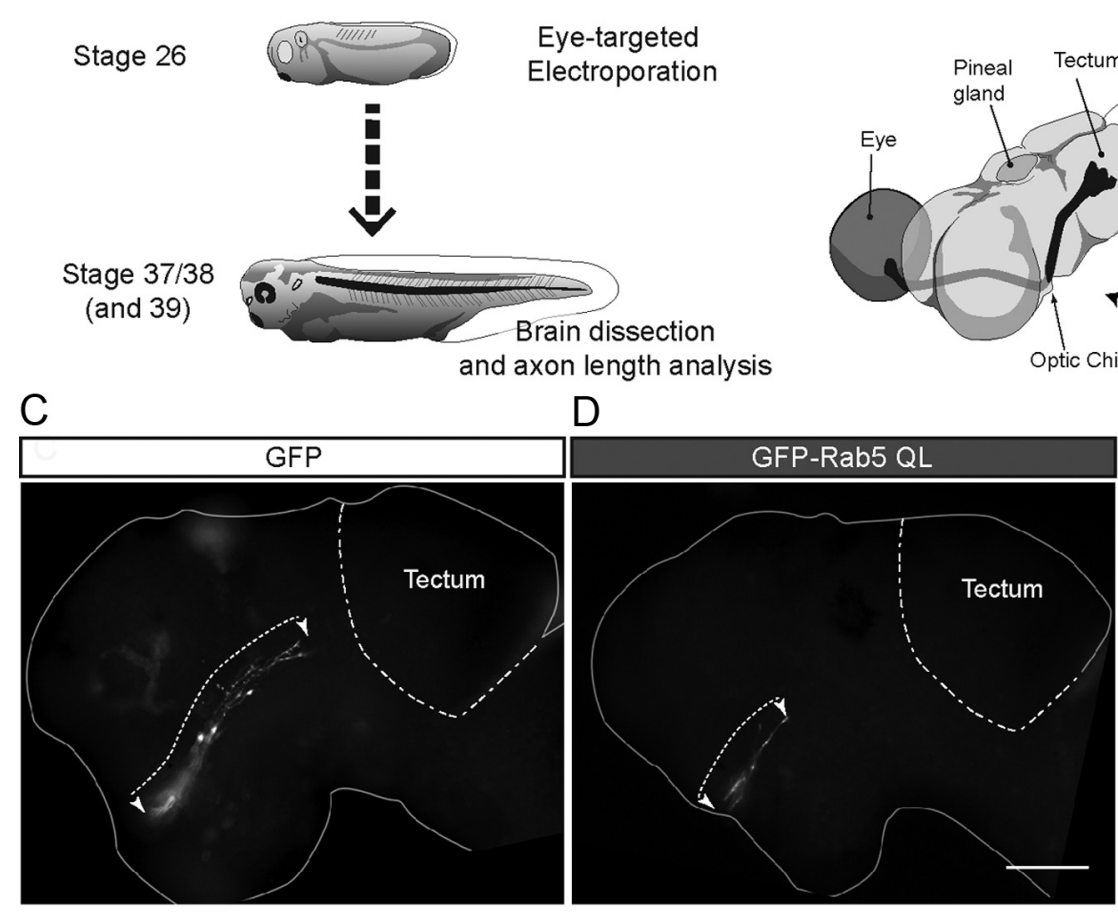

B

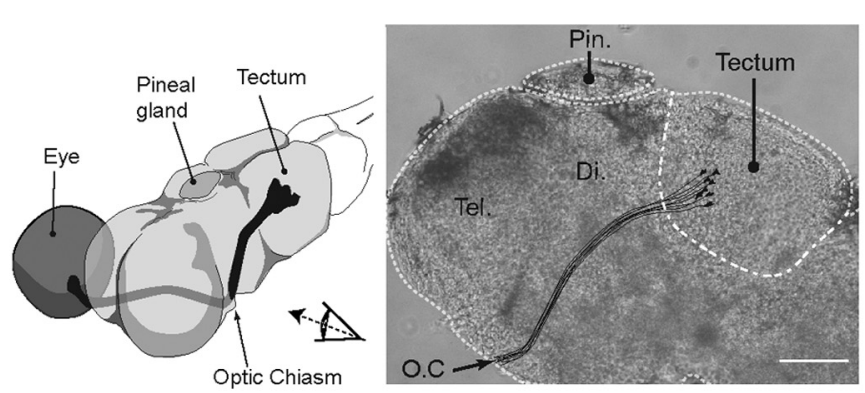

$\mathrm{E}$

Figure 8. Constitutively active Rab5 delays axon arrival at the tectum in vivo. $\boldsymbol{A}$, Schematic representation of the experiment; retinas of Xenopus embryos were electroporated when RGCs are generated, and embryos were killed before or after RGC axons have reached the tectum (i.e., stage 37/38 or 39). $\boldsymbol{B}$, Right, 3D representation of the retino-tectal projection in Xenopus embryo. RGC axons from the contralateral eye (black) enter the brain at the optic chiasm and grow dorsally in the diencephalon before turning caudally to enter their target, the tectum. Left, Phase image of a stage 39 hemi-brain depicts how brain and tectum outlines (dashed lines) are drawn. The normal course and length of the RGC axons is presented (black lines). $\boldsymbol{C}-\boldsymbol{E}$, RGC axons that express CA-Rab5 are shorter than the control. C, D, Lateral views of whole-mount hemi-brain from stage 37/38 embryos show that GFP-expressing axons approach the tectum (C), while (A-GFP-Rab5-expressing ones are still far away $(\boldsymbol{D})$. The length of the longest axons corresponding to the dotted lines $(\boldsymbol{C}, \boldsymbol{D})$ was measured, and the quantifications are presented in $\boldsymbol{E}$. The experiments were performed with the Xenopus CA-Rab5c (xRab5QL) and the zebrafish CA-Rab5c (zRab5c) constructs, and were analyzed at stage $37 / 38$ and stage 39 in both cases. Numbers above the bars indicate the number of embryos analyzed. Error bars represent the SEM. ${ }^{* * *} p<0.001$ vs the control. Scale bars: $\boldsymbol{B}, \boldsymbol{D}, 100 \mu \mathrm{m}$. OC, Optic chiasm; Di., diencephalon; Tel., telencephalon; Pin., pineal gland.

\section{Rab5 and Rab4 are not required for long-range guidance} Growth cone responses to guidance cues depend on endocytosis, and some of the mechanisms to which Rab5-Rab4 recycling could contribute are likely to affect these responses (Fournier et al., 2000; Jurney et al., 2002; Mann et al., 2003; Castellani et al., 2004; Cowan et al., 2005; Piper et al., 2005, 2006; Tojima et al., 2007; Law et al., 2008; Thelen et al., 2008; Kabayama et al., 2009; Kolpak et al., 2009; Carcea et al., 2010; Hines et al., 2010; Joset et al., 2010; Tojima et al., 2010; Yoo et al., 2011). Thus, the absence of a long-range axon guidance phenotype in vivo is puzzling. However, similar to Xenopus RGC axons, axons from Drosophila photoreceptors expressing DN and CA Rabs (4, 5, and 7) also reach their target apparently normally (Zhang et al., 2007). Moreover, none of these Rab mutants impair the guidance of commissural axons (van den Brink et al., 2013). Even if Rabs (4, 5, and 7) are involved in growth cone directional responses to guidance cues, this function might be difficult to detect in vivo. Possibly long-range guidance is resilient because untransfected axons pioneer the tract or because cues less dependent on endocytosis have a greater contribution to their guidance (Harris, 1986; Pittman et al., 2008; Tojima et al., 2010). Recycling is only one of several mechanisms that control guidance receptor availability and signaling (Nawabi et al., 2010). Thus, these additional mechanisms could act redundantly to induce a normal response. Finally, recycling pathways are diverse and involve a wide diversity of molecules that offer many opportunities for compensatory mechanisms (Grant and Donaldson, 2009). Rab-dependent trafficking appears to be particularly resilient (Zeigerer et al., 2012), and other Rabs could compensate for Rab5 or Rab4 functional loss (White et al., 2007; Zhu et al., 2009). Since primaquine has a greater impact on axon growth than the targeting of individual Rabs, alternative recycling pathways probably exist. Rab35 is expressed in stage 32 Xenopus retina and is a likely candidate. Indeed, Rab35 mediates fast recycling, is present on endosomes in growth cones, and promotes neurite formation in neuroendocrine PC12 cells (Kouranti et al., 2006; Chevallier et al., 2009; Nozumi et al., 2009).

\section{Rab5- and Rab4-dependent recycling regulate axon elongation}

Although this is the first demonstration that Rab5 controls axon development in vivo, the role of Rab5 in axon elongation is consistent with previous results. First, manipulations of GEF (Alsin) and GAP (synGAP) suggested that part of their effects on axon formation and elongation depends on Rab5 (Tomoda et al., 2004; Otomo et al., 2008). Second, CA-Rab5 inhibits neurite formation by PC12 cells, and Wt-Rab5 reduces total neurite length of hippocampal neurons in vitro (Liu et al., 2007; Heo et al., 2010).

The function that we ascribe to Rab4 using mutant proteins and morpholinos is, to our knowledge, novel. Indeed, although Rab4 protein is highly enriched in neurites of differentiating $\mathrm{PC} 12$, its functions during neurite formation or axon extension have not been explored (Pertz et al., 2008). The finding that Rab4 controls axon elongation fits well with published data. Since CARab5 impairs neurite formation, it is of note that both DN-Rab4 and CA-Rab5 block recycling and similarly affect the size of early 
A

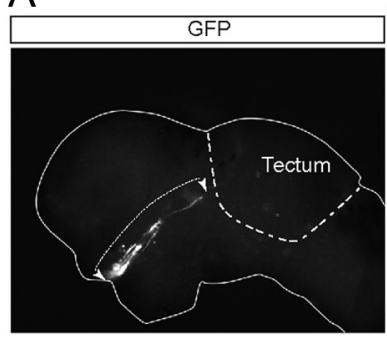

B

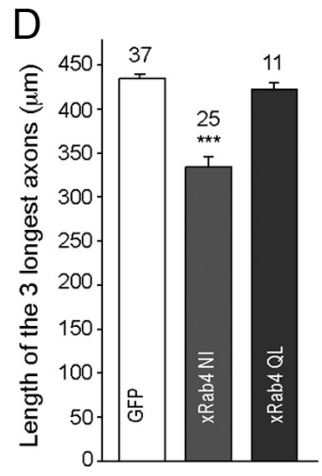

Stage 39

G

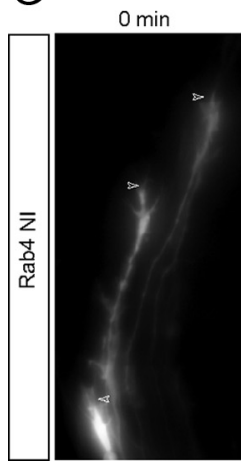

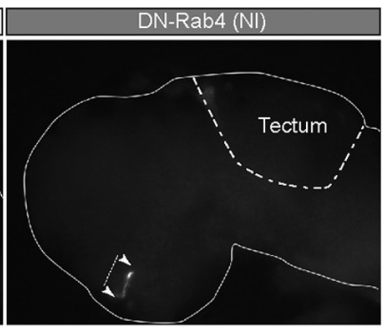

E

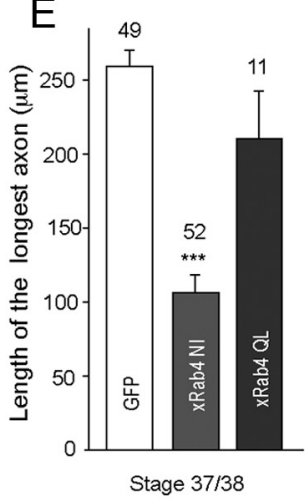

$\mathrm{F}$

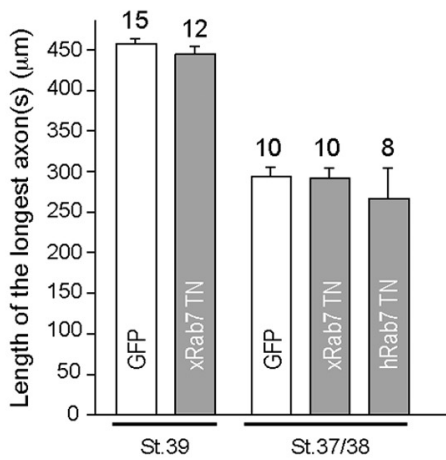

$\mathrm{H}$
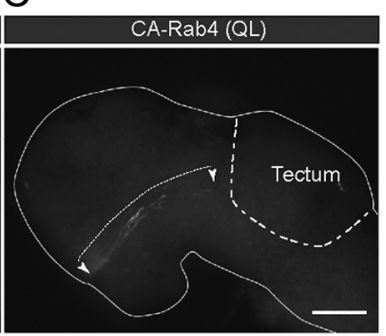

$\min$
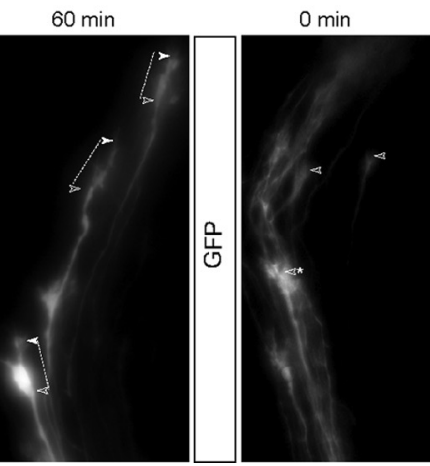
$60 \mathrm{~min}$
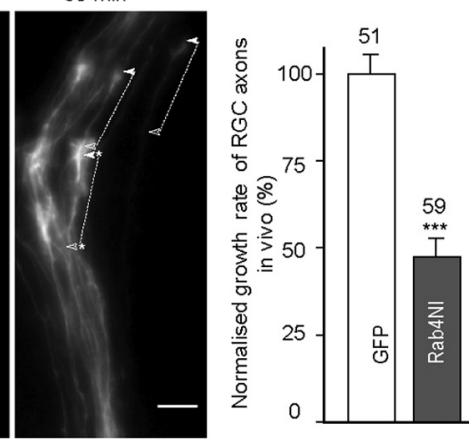

Figure 9. DN-Rab4 delays axon arrival at the tectum and slows axon extension in vivo. $\boldsymbol{A}-\boldsymbol{C}$, Lateral views of stage $37 / 38$ contralateral brains illustrate the length of GFP-positive $(\boldsymbol{A})$, DN-GFP-Rab4-positive $(\boldsymbol{B})$, and CA-GFP-Rab4-positive $(\boldsymbol{C})$ axons. The tectum (dashed line) and the brain (plain line) outlines were drawn from the phase image. Dotted lines between arrowheads exemplify the length of the longest axon. Axons that express GFP $(\boldsymbol{A})$ or GFP-CA-Rab4 (QL mutant; $\boldsymbol{C}$ ) extend equally well along the optic tract. In contrast, DN-Rab4 (NI mutant)-expressing axons are much shorter (B). Lengths of GFP-positive, CA-Rab4-positive, DN-Rab4-positive, and DN-Rab7-positive (Xenopus, human) axons were measured in stage 37/38 and 39 brains. D-F, Summary of the quantifications shows that DN-Rab4 is the only construct tested here that significantly reduces axon length. $\mathbf{G}, \boldsymbol{H}, \mathrm{DN}$-Rab4 decreases axon extension rate in vivo. $\mathbf{G}$, Pictures from in vivo time-lapse sequences show DN-GFP-Rab4-expressing (left) and GFP-expressing (right) axons that extend along the optic tract. Images are z-projections at the 0 and 60 min time points. 0 pen and filled arrowheads indicate the growth cone positions at the start and the end of the $1 \mathrm{~h}$ recording, respectively. Dotted lines exemplify the distance traveled by the growth cones during the $1 \mathrm{~h}$ monitoring. Quantifications of the in vivo time-lapse recordings are presented in $\boldsymbol{H}$. Numbers above bars indicate the number of embryos $(\boldsymbol{D}-\boldsymbol{F})$ or axons $(\boldsymbol{H})$ analyzed. Error bars represent the $S E M$. ${ }^{* * *} p<0.001$ vs the control. Scale bars: $\boldsymbol{C}, 100 \mu \mathrm{m} ; \boldsymbol{G}, 15 \mu \mathrm{m}$.

endosomes (Stenmark et al., 1994; Chavrier et al., 1997; de Wit et al., 2001; Leterrier et al., 2004). Moreover, Rab4 has been shown previously to contribute to cell migration, and the effectors of cell migration and growth cone advance are often the same (White et al., 2007; Witze et al., 2008; Gu et al., 2011).

Rab4 loss of function could potentially affect other recycling pathways, such as Rab11-dependent recycling (Ward et al., 2005). Perturbations of additional pathways could indirectly slow axon extension. Although this cannot be ruled out, the rapid inhibition of both recycling and axon elongation by primaquine, which disturbs Rab4-positive endosomes, supports a direct role of Rab4. Consistent with this, the effect of Rab4 loss-of-function generally differs from Rab11 loss-of-function (Leterrier et al.,
2004; Brown et al., 2007; White et al., 2007; Li et al., 2012). Moreover, the Rab4dependent recycling from Rab5 endosomes we postulate appears particularly adapted to support the fast recycling observed in growth cones and is consistent with the reliance of axon growth on recycling (Diefenbach et al., 1999; Kamiguchi and Yoshihara, 2001; Bonanomi et al., 2008). In addition, the results with primaquine treatment suggest that the Rab4dependent pathway controls the amount and/or the kinetics of recycling cargoes. However, whether, similar to migratory cells, Rab4 loss-of-function impairs recycling of adhesion molecules, such as integrins, remains to be determined. Therefore, alternative hypotheses cannot be disregarded. The effect of Rab4 on axon elongation might be due to changes in early endosome dynamics and be independent of membrane reinsertion per se. Rab5-positive early endosomes regulate, for example, the localization of the NWASP/TOCA-1 complex and Racl that are crucial for growth cone mobility (Palamidessi et al., 2008; Bu et al., 2009). Thus, a decrease of Rab5-positive endosome movements into the peripheral domain could potentially be responsible for changing growth cone motility.

Both the turnover of integrins or the activation of Rac-1 that the Rab4dependent pathway could potentially mediate are particularly interesting links. Indeed, perturbations of integrin or Racl activity inhibit the growth of Xenopus RGC axons in vivo, like Rab5 and Rab4 mutants (Lilienbaum et al., 1995; Ruchhoeft et al., 1999).

Finally, the Rab4-dependent pathway could also contribute to the modulation of growth cone motility. Indeed, the fast bulk recycling that Rab4 may mediate decreases in older neurons (Bonanomi et al., 2008). In addition, intrinsic changes (e.g., calcium activity) or extrinsic cues could modulate Rab4-dependent recycling in axons as occurs in other models (Shirakawa et al., 2000; Roberts et al., 2001; Witze et al., 2008). Both protein levels and activities of Rabs could be modulated and change the magnitude of local recycling (Juvet et al., 1997; Stenmark and Olkkonen, 2001; Liu et al., 2007; Pei et al., 2012). Whether this type of modulation occurs when axons change their elongation rate during their journey remains to be determined. Nonetheless, our results demonstrate that manipulation of Rab5 and Rab4 activity alters axon growth rate and suggest that this is due to deficient recycling within the growth cones.

\section{Notes}

Supplemental material, including movies of the live imaging sequences used in Figures 3 and 4, is available at http://cgphimc.univ-lyon1. 
fr/CGphiMC/Falk/SupJN1.htm. Rab5 and Rab4 regulate axon elongation in the Xenopus visual system. This material has not been peer reviewed.

\section{References}

Archer KJ, Reese SE (2010) Detection call algorithms for high-throughput gene expression microarray data. Brief Bioinform 11:244-252. CrossRef Medline

Ascaño M, Richmond A, Borden P, Kuruvilla R (2009) Axonal targeting of Trk receptors via transcytosis regulates sensitivity to neurotrophin responses. J Neurosci 29:11674-11685. CrossRef Medline

Bananis E, Murray JW, Stockert RJ, Satir P, Wolkoff AW (2003) Regulation of early endocytic vesicle motility and fission in a reconstituted system. J Cell Sci 116:2749-2761. CrossRef Medline

Barbieri MA, Roberts RL, Gumusboga A, Highfield H, Alvarez-Dominguez C, Wells A, Stahl PD (2000) Epidermal growth factor and membrane trafficking. EGF receptor activation of endocytosis requires Rab5a. J Cell Biol 151:539-550. CrossRef Medline

Bergtold A, Desai DD, Gavhane A, Clynes R (2005) Cell surface recycling of internalized antigen permits dendritic cell priming of B cells. Immunity 23:503-514. CrossRef Medline

Bonanomi D, Menegon A, Miccio A, Ferrari G, Corradi A, Kao HT, Benfenati F, Valtorta F (2005) Phosphorylation of synapsin I by cAMP-dependent protein kinase controls synaptic vesicle dynamics in developing neurons. J Neurosci 25:7299-7308. CrossRef Medline

Bonanomi D, Fornasiero EF, Valdez G, Halegoua S, Benfenati F, Menegon A, Valtorta F (2008) Identification of a developmentally regulated pathway of membrane retrieval in neuronal growth cones. J Cell Sci 121:37573769. CrossRef Medline

Brown TC, Correia SS, Petrok CN, Esteban JA (2007) Functional compartmentalization of endosomal trafficking for the synaptic delivery of AMPA receptors during long-term potentiation. J Neurosci 27:13311-13315. CrossRef Medline

Bu W, Chou AM, Lim KB, Sudhaharan T, Ahmed S (2009) The Toca-1-NWASP complex links filopodial formation to endocytosis. J Biol Chem 284:11622-11636. CrossRef Medline

Bucci C, Lütcke A, Steele-Mortimer O, Olkkonen VM, Dupree P, Chiariello M, Bruni CB, Simons K, Zerial M (1995) Co-operative regulation of endocytosis by three Rab5 isoforms. FEBS Lett 366:65-71. CrossRef Medline

Bucci C, Thomsen P, Nicoziani P, McCarthy J, van Deurs B (2000) Rab7: a key to lysosome biogenesis. Mol Biol Cell 11:467-480. CrossRef Medline

Campbell DS, Regan AG, Lopez JS, Tannahill D, Harris WA, Holt CE (2001) Semaphorin 3A elicits stage-dependent collapse, turning, and branching in Xenopus retinal growth cones. J Neurosci 21:8538-8547. Medline

Capps GG, Zúñiga MC (2000) Phosphorylation of class I MHC molecules in the absence of phorbol esters is an intracellular event and may be characteristic of trafficking molecules. Mol Immunol 37:59-71. CrossRef Medline

Carcea I, Ma'ayan A, Mesias R, Sepulveda B, Salton SR, Benson DL (2010) Flotillin-mediated endocytic events dictate cell type-specific responses to semaphorin 3A. J Neurosci 30:15317-15329. CrossRef Medline

Castellani V, Falk J, Rougon G (2004) Semaphorin3A-induced receptor endocytosis during axon guidance responses is mediated by L1 CAM. Mol Cell Neurosci 26:89-100. CrossRef Medline

Chavrier P, van der Sluijs P, Mishal Z, Nagelkerken B, Gorvel JP (1997) Early endosome membrane dynamics characterized by flow cytometry. Cytometry 29:41-49. CrossRef Medline

Chen PI, Kong C, Su X, Stahl PD (2009) Rab5 isoforms differentially regulate the trafficking and degradation of epidermal growth factor receptors. J Biol Chem 284:30328-30338. CrossRef Medline

Chevallier J, Koop C, Srivastava A, Petrie RJ, Lamarche-Vane N, Presley JF (2009) Rab35 regulates neurite outgrowth and cell shape. FEBS Lett 583: 1096-1101. CrossRef Medline

Chien CB, Rosenthal DE, Harris WA, Holt CE (1993) Navigational errors made by growth cones without filopodia in the embryonic Xenopus brain. Neuron 11:237-251. CrossRef Medline

Cormont M, Bortoluzzi MN, Gautier N, Mari M, van Obberghen E, Le Marchand-Brustel Y (1996) Potential role of Rab4 in the regulation of subcellular localization of Glut4 in adipocytes. Mol Cell Biol 16:68796886. Medline

Cowan CW, Shao YR, Sahin M, Shamah SM, Lin MZ, Greer PL, Gao S,
Griffith EC, Brugge JS, Greenberg ME (2005) Vav family GEFs link activated Ephs to endocytosis and axon guidance. Neuron 46:205-217. CrossRef Medline

de Hoop MJ, Huber LA, Stenmark H, Williamson E, Zerial M, Parton RG, Dotti CG (1994) The involvement of the small GTP-binding protein Rab5a in neuronal endocytosis. Neuron 13:11-22. CrossRef Medline

Deinhardt K, Salinas S, Verastegui C, Watson R, Worth D, Hanrahan S, Bucci C, Schiavo G (2006) Rab5 and Rab7 control endocytic sorting along the axonal retrograde transport pathway. Neuron 52:293-305. CrossRef Medline

Deneka M, Neeft M, Popa I, van Oort M, Sprong H, Oorschot V, Klumperman J, Schu P, van der Sluijs P (2003) Rabaptin-5alpha/rabaptin-4 serves as a linker between rab4 and gamma(1)-adaptin in membrane recycling from endosomes. EMBO J 22:2645-2657. CrossRef Medline

de Wit H, Lichtenstein Y, Kelly RB, Geuze HJ, Klumperman J, van der Sluijs P (2001) Rab4 regulates formation of synaptic-like microvesicles from early endosomes in PC12 cells. Mol Biol Cell 12:3703-3715. CrossRef Medline

Diefenbach TJ, Guthrie PB, Stier H, Billups B, Kater SB (1999) Membrane recycling in the neuronal growth cone revealed by FM1-43 labeling. J Neurosci 19:9436-9444. Medline

Diestel S, Schaefer D, Cremer H, Schmitz B (2007) NCAM is ubiquitylated, endocytosed and recycled in neurons. J Cell Sci 120:4035-4049. CrossRef Medline

Dwivedy A, Gertler FB, Miller J, Holt CE, Lebrand C (2007) Ena/VASP function in retinal axons is required for terminal arborization but not pathway navigation. Development 134:2137-2146. CrossRef Medline

Eva R, Dassie E, Caswell PT, Dick G, ffrench-Constant C, Norman JC, Fawcett JW (2010) Rab11 and its effector Rab coupling protein contribute to the trafficking of $\beta 1$ integrins during axon growth in adult dorsal root ganglion neurons and PC12 cells. J Neurosci 30:11654-11669. CrossRef Medline

Falk J, Drinjakovic J, Leung KM, Dwivedy A, Regan AG, Piper M, Holt CE (2007) Electroporation of cDNA/Morpholinos to targeted areas of embryonic CNS in Xenopus. BMC Dev Biol 7:107. CrossRef Medline

Feliciano WD, Yoshida S, Straight SW, Swanson JA (2011) Coordination of the Rab5 cycle on macropinosomes. Traffic 12:1911-1922. CrossRef Medline

Fournier AE, Nakamura F, Kawamoto S, Goshima Y, Kalb RG, Strittmatter SM (2000) Semaphorin3A enhances endocytosis at sites of receptor-Factin colocalization during growth cone collapse. J Cell Biol 149:411-422. CrossRef Medline

Glodowski DR, Chen CC, Schaefer H, Grant BD, Rongo C (2007) RAB-10 regulates glutamate receptor recycling in a cholesterol-dependent endocytosis pathway. Mol Biol Cell 18:4387-4396. CrossRef Medline

Goldberg JL (2003) How does an axon grow? Genes Dev 17:941-958. CrossRef Medline

Gomez TM, Spitzer NC (1999) In vivo regulation of axon extension and pathfinding by growth-cone calcium transients. Nature 397:350-355. CrossRef Medline

Granseth B, Odermatt B, Royle SJ, Lagnado L (2006) Clathrin-mediated endocytosis is the dominant mechanism of vesicle retrieval at hippocampal synapses. Neuron 51:773-786. CrossRef Medline

Grant BD, Donaldson JG (2009) Pathways and mechanisms of endocytic recycling. Nat Rev Mol Cell Biol 10:597-608. CrossRef Medline

$\mathrm{Gu} \mathrm{Z}$, Noss EH, Hsu VW, Brenner MB (2011) Integrins traffic rapidly via circular dorsal ruffles and macropinocytosis during stimulated cell migration. J Cell Biol 193:61-70. CrossRef Medline

Harris WA (1986) Homing behaviour of axons in the embryonic vertebrate brain. Nature 320:266-269. CrossRef Medline

Harris WA, Holt CE, Bonhoeffer F (1987) Retinal axons with and without their somata, growing to and arborizing in the tectum of Xenopus embryos: a time-lapse video study of single fibres in vivo. Development 101:123-133. Medline

Hayakawa A, Hayes S, Leonard D, Lambright D, Corvera S (2007) Evolutionarily conserved structural and functional roles of the FYVE domain. Biochem Soc Symp 95-105. CrossRef Medline

Heo HY, Kim KS, Seol W (2010) Coordinate regulation of neurite outgrowth by LRRK2 and its interactor, Rab5. Exp Neurobiol 19:97-105. CrossRef Medline

Hines JH, Abu-Rub M, Henley JR (2010) Asymmetric endocytosis and re- 
modeling of betal-integrin adhesions during growth cone chemorepulsion by MAG. Nat Neurosci 13:829-837. CrossRef Medline

Hines JH, Henle SJ, Carlstrom LP, Abu-Rub M, Henley JR (2012) Single vesicle imaging indicates distinct modes of rapid membrane retrieval during nerve growth. BMC Biol 10:4. CrossRef Medline

Holmes KD, Babwah AV, Dale LB, Poulter MO, Ferguson SS (2006) Differential regulation of corticotropin releasing factor lalpha receptor endocytosis and trafficking by beta-arrestins and Rab GTPases. J Neurochem 96:934-949. CrossRef Medline

Holt CE (1984) Does timing of axon outgrowth influence initial retinotectal topography in Xenopus? J Neurosci 4:1130-1152. Medline

Holt CE, Harris WA (1983) Order in the initial retinotectal map in Xenopus: a new technique for labelling growing nerve fibres. Nature 301:150152. CrossRef Medline

Hoogenraad CC, Popa I, Futai K, Martinez-Sanchez E, Sanchez-Martinez E, Wulf PS, van Vlijmen T, Dortland BR, Oorschot V, Govers R, Monti M, Heck AJ, Sheng M, Klumperman J, Rehmann H, Jaarsma D, Kapitein LC, van der Sluijs P (2010) Neuron specific Rab4 effector GRASP-1 coordinates membrane specialization and maturation of recycling endosomes. PLoS Biol 8:e1000283. CrossRef Medline

Horiuchi H, Giner A, Hoflack B, Zerial M (1995) A GDP/GTP exchangestimulatory activity for the Rab5-RabGDI complex on clathrin-coated vesicles from bovine brain. J Biol Chem 270:11257-11262. CrossRef Medline

Jones MC, Caswell PT, Moran-Jones K, Roberts M, Barry ST, Gampel A, Mellor H, Norman JC (2009) VEGFR1 (Flt1) regulates Rab4 recycling to control fibronectin polymerization and endothelial vessel branching. Traffic 10:754-766. CrossRef Medline

Joset A, Dodd DA, Halegoua S, Schwab ME (2010) Pincher-generated Nogo-A endosomes mediate growth cone collapse and retrograde signaling. J Cell Biol 188:271-285. CrossRef Medline

Jullien J, Gurdon J (2005) Morphogen gradient interpretation by a regulated trafficking step during ligand-receptor transduction. Genes Dev 19: 2682-2694. CrossRef Medline

Jurney WM, Gallo G, Letourneau PC, McLoon SC (2002) Rac1-mediated endocytosis during ephrin-A2- and semaphorin 3A-induced growth cone collapse. J Neurosci 22:6019-6028. Medline

Juvet LK, Berg T, Gjøen T (1997) The expression of endosomal rab proteins correlates with endocytic rate in rat liver cells. Hepatology 25:1204-1212. CrossRef Medline

Kabayama H, Nakamura T, Takeuchi M, Iwasaki H, Taniguchi M, Tokushige N, Mikoshiba K (2009) Ca2 + induces macropinocytosis via F-actin depolymerization during growth cone collapse. Mol Cell Neurosci 40:2738. CrossRef Medline

Kaddai V, Gonzalez T, Keslair F, Grémeaux T, Bonnafous S, Gugenheim J, Tran A, Gual P, Le Marchand-Brustel Y, Cormont M (2009) Rab4b is a small GTPase involved in the control of the glucose transporter GLUT4 localization in adipocyte. PLoS One 4:e5257. CrossRef Medline

Kamiguchi H, Lemmon V (2000) Recycling of the cell adhesion molecule L1 in axonal growth cones. J Neurosci 20:3676-3686. Medline

Kamiguchi H, Yoshihara F (2001) The role of endocytic 11 trafficking in polarized adhesion and migration of nerve growth cones. J Neurosci 21: 9194-9203. Medline

Kolpak AL, Jiang J, Guo D, Standley C, Bellve K, Fogarty K, Bao ZZ (2009) Negative guidance factor-induced macropinocytosis in the growth cone plays a critical role in repulsive axon turning. J Neurosci 29:10488-10498. CrossRef Medline

Kouranti I, Sachse M, Arouche N, Goud B, Echard A (2006) Rab35 regulates an endocytic recycling pathway essential for the terminal steps of cytokinesis. Curr Biol 16:1719-1725. CrossRef Medline

Lapierre LA, Dorn MC, Zimmerman CF, Navarre J, Burnette JO, Goldenring JR (2003) Rab11b resides in a vesicular compartment distinct from Rab1la in parietal cells and other epithelial cells. Exp Cell Res 290:322331. CrossRef Medline

Law CO, Kirby RJ, Aghamohammadzadeh S, Furley AJ (2008) The neural adhesion molecule TAG-1 modulates responses of sensory axons to diffusible guidance signals. Development 135:2361-2371. CrossRef Medline

Leterrier C, Bonnard D, Carrel D, Rossier J, Lenkei Z (2004) Constitutive endocytic cycle of the CB1 cannabinoid receptor. J Biol Chem 279:3601336021. CrossRef Medline

Leung KM, Holt CE (2008) Live visualization of protein synthesis in axonal growth cones by microinjection of photoconvertible Kaede into Xenopus embryos. Nat Protoc 3:1318-1327. CrossRef Medline

Li Y, Roy BD, Wang W, Zhang L, Zhang L, Sampson SB, Yang Y, Lin DT (2012) Identification of two functionally distinct endosomal recycling pathways for dopamine $\mathrm{D}_{2}$ receptor. J Neurosci 32:7178-7190. CrossRef Medline

Lilienbaum A, Reszka AA, Horwitz AF, Holt CE (1995) Chimeric integrins expressed in retinal ganglion cells impair process outgrowth in vivo. Mol Cell Neurosci 6:139-152. CrossRef Medline

Liu J, Lamb D, Chou MM, Liu YJ, Li G (2007) Nerve growth factormediated neurite outgrowth via regulation of Rab5. Mol Biol Cell 18: 1375-1384. CrossRef Medline

Mann F, Miranda E, Weinl C, Harmer E, Holt CE (2003) B-type Eph receptors and ephrins induce growth cone collapse through distinct intracellular pathways. J Neurobiol 57:323-336. CrossRef Medline

Maxfield FR, McGraw TE (2004) Endocytic recycling. Nat Rev Mol Cell Biol 5:121-132. CrossRef Medline

McCaffrey MW, Bielli A, Cantalupo G, Mora S, Roberti V, Santillo M, Drummond F, Bucci C (2001) Rab4 affects both recycling and degradative endosomal trafficking. FEBS Lett 495:21-30. CrossRef Medline

McFarlane S, Cornel E, Amaya E, Holt CE (1996) Inhibition of FGF receptor activity in retinal ganglion cell axons causes errors in target recognition. Neuron 17:245-254. CrossRef Medline

Meijering E, Jacob M, Sarria JC, Steiner P, Hirling H, Unser M (2004) Design and validation of a tool for neurite tracing and analysis in fluorescence microscopy images. Cytometry A 58:167-176. Medline

Miaczynska M, Zerial M (2002) Mosaic organization of the endocytic pathway. Exp Cell Res 272:8-14. CrossRef Medline

Mire E, Mezzera C, Leyva- Díaz E, Paternain AV, Squarzoni P, Bluy L, Castillo-Paterna M, López MJ, Peregrín S, Tessier-Lavigne M, Garel S, Galcerán J, Lerma J, López -Bendito G (2012) Spontaneous activity regulates Robol transcription to mediate a switch in thalamocortical axon growth. Nat Neurosci 15:1134-1143. CrossRef Medline

Mukhopadhyay A, Funato K, Stahl PD (1997) Rab7 regulates transport from early to late endocytic compartments in Xenopus oocytes. J Biol Chem 272:13055-13059. CrossRef Medline

Nakazawa H, Sada T, Toriyama M, Tago K, Sugiura T, Fukuda M, Inagaki N (2012) Rab33a mediates anterograde vesicular transport for membrane exocytosis and axon outgrowth. J Neurosci 32:12712-12725. CrossRef Medline

Nawabi H, Briançon-Marjollet A, Clark C, Sanyas I, Takamatsu H, Okuno T, Kumanogoh A, Bozon M, Takeshima K, Yoshida Y, Moret F, Abouzid K, Castellani V (2010) A midline switch of receptor processing regulates commissural axon guidance in vertebrates. Genes Dev 24:396-410. CrossRef Medline

Nieuwkoop PD, Faber J (1994) Normal table of Xenopus laevis (Daudin). New York: Garland.

Nozumi M, Togano T, Takahashi-Niki K, Lu J, Honda A, Taoka M, Shinkawa $\mathrm{T}$, Koga H, Takeuchi K, Isobe T, Igarashi M (2009) Identification of functional marker proteins in the mammalian growth cone. Proc Natl Acad Sci U S A 106:17211-17216. CrossRef Medline

Otomo A, Kunita R, Suzuki-Utsunomiya K, Mizumura H, Onoe K, Osuga H, Hadano S, Ikeda JE (2008) ALS2/alsin deficiency in neurons leads to mild defects in macropinocytosis and axonal growth. Biochem Biophys Res Commun 370:87-92. CrossRef Medline

Pagano A, Crottet P, Prescianotto-Baschong C, Spiess M (2004) In vitro formation of recycling vesicles from endosomes requires adaptor protein$1 /$ clathrin and is regulated by rab 4 and the connector rabaptin-5. Mol Biol Cell 15:4990-5000. CrossRef Medline

Palamidessi A, Frittoli E, Garré M, Faretta M, Mione M, Testa I, Diaspro A, Lanzetti L, Scita G, Di Fiore PP (2008) Endocytic trafficking of Rac is required for the spatial restriction of signaling in cell migration. Cell 134:135-147. CrossRef Medline

Panicker AK, Buhusi M, Erickson A, Maness PF (2006) Endocytosis of betal integrins is an early event in migration promoted by the cell adhesion molecule L1. Exp Cell Res 312:299-307. CrossRef Medline

Pei G, Bronietzki M, Gutierrez MG (2012) Immune regulation of Rab proteins expression and intracellular transport. J Leukoc Biol 92:41-50. CrossRef Medline

Pertz OC, Wang Y, Yang F, Wang W, Gay LJ, Gristenko MA, Clauss TR, Anderson DJ, Liu T, Auberry KJ, Camp DG 2nd, Smith RD, Klemke RL (2008) Spatial mapping of the neurite and soma proteomes reveals a 
functional Cdc42/Rac regulatory network. Proc Natl Acad Sci U S A 105: 1931-1936. CrossRef Medline

Piper M, Salih S, Weinl C, Holt CE, Harris WA (2005) Endocytosisdependent desensitization and protein synthesis-dependent resensitization in retinal growth cone adaptation. Nat Neurosci 8:179-186. CrossRef Medline

Piper M, Anderson R, Dwivedy A, Weinl C, van Horck F, Leung KM, Cogill E, Holt C (2006) Signaling mechanisms underlying Slit2-induced collapse of Xenopus retinal growth cones. Neuron 49:215-228. CrossRef Medline

Pittman AJ, Law MY, Chien CB (2008) Pathfinding in a large vertebrate axon tract: isotypic interactions guide retinotectal axons at multiple choice points. Development 135:2865-2871. CrossRef Medline

Portera-Cailliau C, Weimer RM, De Paola V, Caroni P, Svoboda K (2005) Diverse modes of axon elaboration in the developing neocortex. PLoS Biol 3:e272. CrossRef Medline

Prigozhina NL, Waterman-Storer CM (2006) Decreased polarity and increased random motility in PtK1 epithelial cells correlate with inhibition of endosomal recycling. J Cell Sci 119:3571-3582. CrossRef Medline

Raiborg C, Bremnes B, Mehlum A, Gillooly DJ, D’Arrigo A, Stang E, Stenmark H (2001) FYVE and coiled-coil domains determine the specific localisation of Hrs to early endosomes. J Cell Sci 114:2255-2263. Medline

Reid PA, Watts C (1990) Cycling of cell-surface MHC glycoproteins through primaquine-sensitive intracellular compartments. Nature 346: 655-657. CrossRef Medline

Ren M, Xu G, Zeng J, De Lemos-Chiarandini C, Adesnik M, Sabatini DD (1998) Hydrolysis of GTP on rab11 is required for the direct delivery of transferrin from the pericentriolar recycling compartment to the cell surface but not from sorting endosomes. Proc Natl Acad Sci U S A 95:61876192. CrossRef Medline

Rink J, Ghigo E, Kalaidzidis Y, Zerial M (2005) Rab conversion as a mechanism of progression from early to late endosomes. Cell 122:735-749. CrossRef Medline

Roberts M, Barry S, Woods A, van der Sluijs P, Norman J (2001) PDGFregulated rab4-dependent recycling of alphavbeta3 integrin from early endosomes is necessary for cell adhesion and spreading. Curr Biol 11: 1392-1402. CrossRef Medline

Roberts RL, Barbieri MA, Ullrich J, Stahl PD (2000) Dynamics of rab5 activation in endocytosis and phagocytosis. J Leukoc Biol 68:627-632. Medline

Roman-Vendrell C, Yu YJ, Yudowski GA (2012) Fast modulation of muopioid receptor (MOR) recycling is mediated by receptor agonists. J Biol Chem 287:14782-14791. CrossRef Medline

Ruchhoeft ML, Ohnuma S, McNeill L, Holt CE, Harris WA (1999) The neuronal architecture of Xenopus retinal ganglion cells is sculpted by rhofamily GTPases in vivo. J Neurosci 19:8454-8463. Medline

Sabo SL, McAllister AK (2003) Mobility and cycling of synaptic proteincontaining vesicles in axonal growth cone filopodia. Nat Neurosci 6:1264-1269. CrossRef Medline

Sato M, Sato K, Fonarev P, Huang CJ, Liou W, Grant BD (2005) Caenorhabditis elegans RME-6 is a novel regulator of RAB-5 at the clathrin-coated pit. Nat Cell Biol 7:559-569. CrossRef Medline

Scapin SM, Carneiro FR, Alves AC, Medrano FJ, Guimarães BG, Zanchin NI (2006) The crystal structure of the small GTPase Rab11b reveals critical differences relative to the Rab1la isoform. J Struct Biol 154:260-268. CrossRef Medline

Schnatwinkel C, Christoforidis S, Lindsay MR, Uttenweiler-Joseph S, Wilm M, Parton RG, Zerial M (2004) The Rab5 effector Rabankyrin-5 regulates and coordinates different endocytic mechanisms. PLoS Biol 2:E261. CrossRef Medline

Schwartz AL, Bolognesi A, Fridovich SE (1984) Recycling of the asialoglycoprotein receptor and the effect of lysosomotropic amines in hepatoma cells. J Cell Biol 98:732-738. CrossRef Medline

Shirakawa R, Yoshioka A, Horiuchi H, Nishioka H, Tabuchi A, Kita T (2000) Small GTPase Rab4 regulates Ca2+-induced alpha-granule secretion in platelets. J Biol Chem 275:33844-33849. CrossRef Medline

Sönnichsen B, De Renzis S, Nielsen E, Rietdorf J, Zerial M (2000) Distinct membrane domains on endosomes in the recycling pathway visualized by multicolor imaging of Rab4, Rab5, and Rab11. J Cell Biol 149:901-914. CrossRef Medline

Stenmark H (2009) Rab GTPases as coordinators of vesicle traffic. Nat Rev Mol Cell Biol 10:513-525. CrossRef Medline
Stenmark H, Olkkonen VM (2001) The Rab GTPase family. Genome Biol 2:REVIEWS3007. CrossRef Medline

Stenmark H, Parton RG, Steele-Mortimer O, Lütcke A, Gruenberg J, Zerial M (1994) Inhibition of rab5 GTPase activity stimulates membrane fusion in endocytosis. EMBO J 13:1287-1296. Medline

Stoorvogel W, Geuze HJ, Strous GJ (1987) Sorting of endocytosed transferrin and asialoglycoprotein occurs immediately after internalization in HepG2 cells. J Cell Biol 104:1261-1268. CrossRef Medline

Strachan LR, Condic ML (2004) Cranial neural crest recycle surface integrins in a substratum-dependent manner to promote rapid motility. J Cell Biol 167:545-554. CrossRef Medline

Tebar F, Villalonga P, Sorkina T, Agell N, Sorkin A, Enrich C (2002) Calmodulin regulates intracellular trafficking of epidermal growth factor receptor and the MAPK signaling pathway. Mol Biol Cell 13:2057-2068. CrossRef Medline

Thelen K, Georg T, Bertuch S, Zelina P, Pollerberg GE (2008) Ubiquitination and endocytosis of cell adhesion molecule DM-GRASP regulate its cell surface presence and affect its role for axon navigation. J Biol Chem 283:32792-32801. CrossRef Medline

Tojima T, Akiyama H, Itofusa R, Li Y, Katayama H, Miyawaki A, Kamiguchi $\mathrm{H}$ (2007) Attractive axon guidance involves asymmetric membrane transport and exocytosis in the growth cone. Nat Neurosci 10:58-66. CrossRef Medline

Tojima T, Itofusa R, Kamiguchi H (2010) Asymmetric clathrin-mediated endocytosis drives repulsive growth cone guidance. Neuron 66:370-377. CrossRef Medline

Tomoda T, Kim JH, Zhan C, Hatten ME (2004) Role of Unc51.1 and its binding partners in CNS axon outgrowth. Genes Dev 18:541-558. CrossRef Medline

Ullrich O, Reinsch S, Urbé S, Zerial M, Parton RG (1996) Rab11 regulates recycling through the pericentriolar recycling endosome. J Cell Biol 135: 913-924. CrossRef Medline

Ulrich F, Krieg M, Schötz EM, Link V, Castanon I, Schnabel V, Taubenberger A, Mueller D, Puech PH, Heisenberg CP (2005) Wnt11 functions in gastrulation by controlling cell cohesion through Rab5c and E-cadherin. Dev Cell 9:555-564. CrossRef Medline

van den Brink DM, Banerji O, Tear G (2013) Commissureless regulation of axon outgrowth across the midline is independent of Rab function. PLoS One 8:e64427. CrossRef Medline

van der Sluijs P, Hull M, Webster P, Mâle P, Goud B, Mellman I (1992) The small GTP-binding protein rab4 controls an early sorting event on the endocytic pathway. Cell 70:729-740. CrossRef Medline

van Weert AW, Geuze HJ, Groothuis B, Stoorvogel W (2000) Primaquine interferes with membrane recycling from endosomes to the plasma membrane through a direct interaction with endosomes which does not involve neutralisation of endosomal $\mathrm{pH}$ nor osmotic swelling of endosomes. Eur J Cell Biol 79:394-399. CrossRef Medline

Visel A, Thaller C, Eichele G (2004) GenePaint.org: an atlas of gene expression patterns in the mouse embryo. Nucleic Acids Res 32:D552-556. CrossRef Medline

Ward ES, Martinez C, Vaccaro C, Zhou J, Tang Q, Ober RJ (2005) From sorting endosomes to exocytosis: association of Rab4 and Rab11 GTPases with the Fc receptor, FcRn, during recycling. Mol Biol Cell 16:2028-2038. CrossRef Medline

Weigert R, Yeung AC, Li J, Donaldson JG (2004) Rab22a regulates the recycling of membrane proteins internalized independently of clathrin. Mol Biol Cell 15:3758-3770. CrossRef Medline

White DP, Caswell PT, Norman JC (2007) alpha v beta3 and alpha5betal integrin recycling pathways dictate downstream Rho kinase signaling to regulate persistent cell migration. J Cell Biol 177:515-525. CrossRef Medline

Wilson JM, de Hoop M, Zorzi N, Toh BH, Dotti CG, Parton RG (2000) EEA1, a tethering protein of the early sorting endosome, shows a polarized distribution in hippocampal neurons, epithelial cells, and fibroblasts. Mol Biol Cell 11:2657-2671. CrossRef Medline

Witze ES, Litman ES, Argast GM, Moon RT, Ahn NG (2008) Wnt5a control of cell polarity and directional movement by polarized redistribution of adhesion receptors. Science 320:365-369. CrossRef Medline

Woo S, Gomez TM (2006) Racl and RhoA promote neurite outgrowth through formation and stabilization of growth cone point contacts. J Neurosci 26:1418-1428. CrossRef Medline

Woolworth JA, Nallamothu G, Hsu T (2009) The Drosophila metastasis 
suppressor gene $\mathrm{Nm} 23$ homolog, awd, regulates epithelial integrity during oogenesis. Mol Cell Biol 29:4679-4690. CrossRef Medline

Yamamoto H, Koga H, Katoh Y, Takahashi S, Nakayama K, Shin HW (2010) Functional cross-talk between Rab14 and Rab4 through a dual effector, RUFY1/Rabip4. Mol Biol Cell 21:2746-2755. CrossRef Medline

Yoo S, Kim Y, Noh H, Lee H, Park E, Park S (2011) Endocytosis of EphA receptors is essential for the proper development of the retinocollicular topographic map. EMBO J 30:1593-1607. CrossRef Medline

Zeigerer A, Gilleron J, Bogorad RL, Marsico G, Nonaka H, Seifert S, EpsteinBarash H, Kuchimanchi S, Peng CG, Ruda VM, Del Conte-Zerial P, Hengstler JG, Kalaidzidis Y, Koteliansky V, Zerial M (2012) Rab5 is necessary for the biogenesis of the endolysosomal system in vivo. Nature 485:465-470. CrossRef Medline
Zhang J, Schulze KL, Hiesinger PR, Suyama K, Wang S, Fish M, Acar M, Hoskins RA, Bellen HJ, Scott MP (2007) Thirty-one flavors of Drosophila rab proteins. Genetics 176:1307-1322. CrossRef Medline

Zhu H, Liang Z, Li G (2009) Rabex-5 is a Rab22 effector and mediates a Rab22-Rab5 signaling cascade in endocytosis. Mol Biol Cell 20:4720 4729. CrossRef Medline

Zivraj KH, Tung YC, Piper M, Gumy L, Fawcett JW, Yeo GS, Holt CE (2010) Subcellular profiling reveals distinct and developmentally regulated repertoire of growth cone mRNAs. J Neurosci 30:15464-15478. CrossRef Medline

Zolessi FR, Poggi L, Wilkinson CJ, Chien CB, Harris WA (2006) Polarization and orientation of retinal ganglion cells in vivo. Neural Dev 1:2. CrossRef Medline 